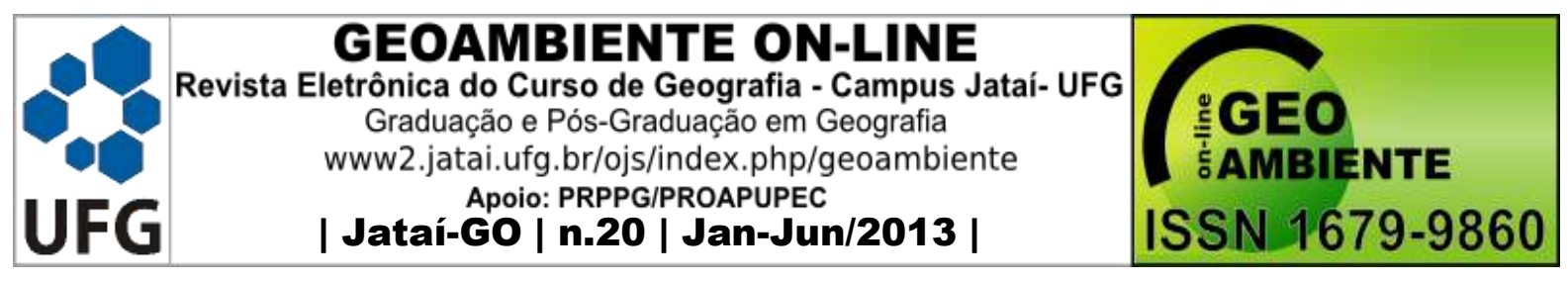

\title{
CORRELAÇÃO DA VARIAÇÃO DA TEMPERATURA NA PARTE SUL DO OCEANO ATLÂNTICO COM O NÚMERO DE DIAS DE PRECIPITAÇÃO PLUVIOMÉTRICA DO ESTADO DO MATO GROSSO DO SUL
}

\author{
Nayhara de Lima Oliveira ${ }^{1}$; Francisco Fernando Noronha Marcuzzo ${ }^{2}$ \\ (1 - Instituto Federal de Goiás, nayhara_lo@hotmail.com; 2 - Serviço Geológico do Brasil, \\ CPRM-RS, francisco.marcuzzo@cprm.gov.br)
}

\section{Resumo}

Um melhor detalhamento do comportamento da precipitação pluvial, com vistas ao seu entendimento e aproveitamento máximo nas atividades humanas, pode ser obtido com o estudo do Número de Dias de Chuva (NDC) e a sua correlação com fenômenos climáticos. O presente trabalho teve como objetivo correlacionar a variação do NDC no Estado do Mato Grosso do Sul com a intensidade das variações de Temperatura da Superfície do Mar (TSM) do Oceano Atlântico Sul. Utilizaram-se dados de 37 estações pluviométricas com 30 anos de dados e 55 estações com dados variando de 20 a 29 anos, sendo que toda série histórica esta entre os anos de 1982 a 2006. Os dados mensais de intensidade das variações TSM do Oceano Atlântico Sul foram obtidos do Serviço Climatológico Nacional dos Estados Unidos, os quais foram relacionados com os dados mensais do NDC. No período de 1982 a 2006 a variação TSM mensal média variou entre $-0,7^{\circ} \mathrm{C}$ e $0,3^{\circ} \mathrm{C}$, a maior variação TSM negativa foi de $-1,0^{\circ} \mathrm{C}$ e a maior variação TSM positiva foi de $0,8^{\circ} \mathrm{C}$. No geral o NDC de cada ano cresceu e diminuiu proporcionalmente tanto nos episódios de variações TSM negativas quanto nos episódios de variação TSM positiva, não permitindo assim delimitar qual das variações TSM mais influência no NDC. Assim conclui-se que as variações TSM não causam efeitos evidentes no NDC do Estado de Mato Grosso do Sul.

Palavras-chave: Temperatura da Superfície do Mar, Número de Dias de Chuva, Oceano Atlântico.

\section{Abstract}

Artigo recebido para publicação em 09 de Dezembro de 2012

Artigo aprovado para publicação em 25 de Março de 2013 


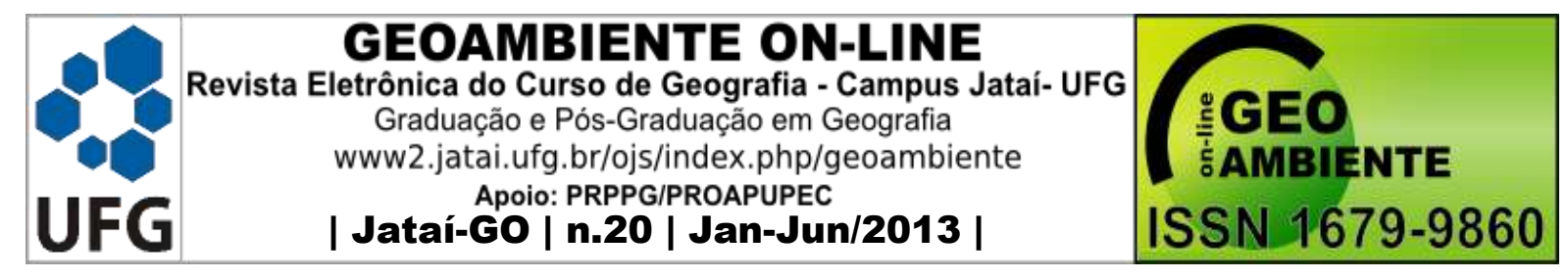

CORRELATION OF TEMPERATURE CHANGES ON THE SOUTH ATLANTIC OCEAN TO THE NUMBER OF DAYS OF RAIN STATE OF MATO GROSSO DO

\section{SUL - BRAZIL}

A more detailed behavior of rainfall, with a view to their understanding and maximum use in human activities, can be obtained from the study of Number of Days Rain (NDC) and its correlation with weather phenomena. This study aimed to correlate the variation of the NDC in the state of Mato Grosso do Sul and the intensity variations of sea surface temperature (SST) of the South Atlantic Ocean We used data from 37 rainfall stations with 30 years of data and 55 stations with data ranging from 20 to 29 years, and throughout this series between the years 1982 to 2006. Monthly data of intensity variations TSM South Atlantic Ocean were obtained from the National Service Climatologic U.S., which were related to monthly data from NDC. From 1982 to 2006 TSM average monthly variation varied between $-0.7^{\circ} \mathrm{C}$ and $0.3^{\circ} \mathrm{C}$, the highest variation was negative TSM $-1.0^{\circ} \mathrm{C}$ and most TSM positive variation was $0.8^{\circ} \mathrm{C}$. Overall the NDC has grown each year and decreased proportionally in both episodes as negative SST variations in episodes of positive SST variation, not allowing delineate which of SST variations influence over the NDC. Thus we conclude that the SST variations do not cause obvious effects NDC in the State of Mato Grosso do Sul

Keywords: Sea Surface Temperature, Number of Days of Rain, Ocean.

\section{Resumem}

CORRELACIÓN DE VARIACIÓN DE LA TEMPERATURA EN EL OCÉANO ATLÁNTICO SUR Y EL NÚMERO DE DÍAS DE LLUVIA EN LA PROVINCIA DE MATO GROSSO DO SUL - BRASIL

Un comportamiento más detallada de la precipitación, con miras a su comprensión y uso máximo de las actividades humanas, se pueden obtener a partir del estudio de Número de días de lluvia (NDC) y su correlación con los fenómenos meteorológicos. Este estudio tuvo como objetivo relacionar la variación de la CND en el estado de Mato Grosso do Sul y las variaciones de intensidad de la temperatura superficial del mar (TSM) en el Océano Atlántico Sur Se utilizaron los datos de 37 estaciones pluviométricas con 30 años de datos y 55 estaciones con datos que van desde 20 a 29 años, ya lo largo de esta serie entre los años 1982 y 2006. Los datos mensuales de las variaciones de intensidad TSM Océano Atlántico Sur se obtuvieron del Servicio Nacional Climatológica de EE.UU., que se relacionan con los datos 


\begin{tabular}{|c|c|c|}
\hline & $\begin{array}{r}\text { GEOAMBIENTE } \\
\text { Revista Eletrônica do Curso de Geog } \\
\text { Graduacão e Pós-Graduacă } \\
\text { www2.jatai.ufg.br/ojs/index } \\
\text { Apoio: PRPPG/PROA } \\
\text { | Jataí-GO | n.20 | Ja }\end{array}$ & ISSN $1679-9860$ \\
\hline
\end{tabular}

mensuales del NDC. De 1982 a 2006 TSM promedio de variación mensual varía entre $-0,7^{\circ} \mathrm{C}$ y $0,3^{\circ} \mathrm{C}$, la mayor variación negativa de $\mathrm{TSM}-1,0^{\circ} \mathrm{C}$ y la mayor variación positiva de TSM fue de $0,8^{\circ} \mathrm{C}$. En general, el NDC ha crecido cada año y disminuyó proporcionalmente en ambos episodios negativos como las variaciones de la TSM en episodios de variación positiva SST, no permitiendo delinear cuál de las variaciones de la TSM influencia sobre el NDC. Así llegamos a la conclusión de que las variaciones de la TSM no causan efectos obvios NDC en el Estado de Mato Grosso do Sul.

Palabras clave: Temperatura Superficial del Mar, Número de Días de Iluvia, Océano Atlántico.

\section{INTRODUÇÃO}

Estudos das variações de temperatura das águas no Oceano Atlântico comprovam a influência dos fenômenos oceânicos sob o ciclo hidrológico e salientam a importância de estudos sobre o comportamento pluviométrico, que possibilitem diagnosticar possíveis desequilíbrios atmosféricos, os quais afetama disponibilidade de recursos naturais e consequentemente o desenvolvimento da região atingida. Com uma economia ligada ao setor agropecuário, o Estado de Mato Grosso do Sul careci de informações sobre o ciclo hidrológico, visando o progresso de suas atividades econômicas. Devido à grande dificuldade de consistência de dados, grande espaçamento físico entre as localizações das estações pluviométricas, pequeno espaçamento temporal de dados pluviométricos, notadamente escassos no Estado do Mato Grosso do Sul, há uma carência muito acentuada de estudos que mostrem a correlação de chuvas neste Estado com as anomalias de temperatura da superfície do Oceano Atlântico.

Mudanças e variabilidades climáticas ameaçam a disponibilidade de água de muitas regiões do mundo, afetando não apenas o abastecimento doméstico e industrial de água, a irrigação e a geração hidroelétrica, como também a segurança e a qualidade dos ambientes naturais e urbanos, por meio do aumento de cheias, secas e da erosão, com consequente decréscimo da qualidade da água e da diversidade dos ecossistemas (Wagener et al., 2005).

A população rural, principalmente a que vive em regiões vulneráveis aos impactos da variabilidade climática, como é o caso do Nordeste do Brasil (NEB), pode usar as previsões climáticas para o melhor gerenciamento de seus recursos, que resultará numa ampliação da produção, diminuindo, desta forma, a desigualdade social. Verifica-se assim, que estas 


\begin{tabular}{|c|c|c|}
\hline & $\begin{array}{r}\text { GEOAMBIENTE } \\
\text { Revista Eletrônica do Curso de Geog } \\
\text { Graduacão e Pós-Graduacă } \\
\text { www2.jatai.ufg.br/ojs/index } \\
\text { Apoio: PRPPG/PROA } \\
\text { | Jataí-GO | n.20 | Ja }\end{array}$ & ISSN $1679-9860$ \\
\hline
\end{tabular}

previsões são imprescindíveis ao planejamento da sociedade como um todo, do ponto de vista social e econômico (Silva et al., 2011). Com esse mesmo proposito Santos e Brito (2007) correlacionaram índices de extremos climáticos com as Anomalias de Temperatura da Superfície do Mar (ATSM), mostrando a partir desse estudo a tendência de aumento da precipitação total anual nos Estados da Paraíba e Rio Grande do Norte.

Experimentos numéricos realizados por Fu et al. (2001) demonstraram que a TSM do Atlântico tropical exerce influência na precipitação da parte leste da região Amazônica equatorial nas estações equinociais e nas estações de solstício esta influência é reduzida.

A precipitação pluvial medida em estações meteorológicas nem sempre é um bom parâmetro para avaliar se a disponibilidade hídrica em determinado período é suficiente para o atendimento das necessidades das culturas agrícolas. Os totais de precipitação pluvial correspondem a todo o período considerado, não sendo levado em conta se foram bem distribuídos ao longo do período ou se ocorreram em um único dia (Fischer et al., 2008). Assim quantificar os dias com chuva e os dias sem chuva de uma região é uma ferramenta à mais para prever possíveis eventos climáticos extremos, como por exemplo, dias consecutivos de chuva ou seca.

Menezes et al. (2008) destacam a importância da precipitação pluvial para o desenvolvimento econômico/social. Segundo Menezes et al. (2008) o conhecimento da distribuição espacial e temporal de veranicos (fenômeno que se caracteriza por períodos de interrupção de precipitação durante a estação chuvosa) em microrregiões, bem como a influência das anomalias de TSM dos oceanos tropicais nas possíveis durações de veranicos, é de grande importância para a tomada de decisões por parte dos governos e da sociedade civil.

Diante da escassez de estudos e pesquisas sobre da influência da variação da temperatura na parte sul do Oceano Atlântico na região centro-oeste do Brasil, bem como suas consequências no âmbito da distribuição temporal das chuvas; o objetivo deste estudo é analisar o impacto da variação da temperatura na parte sul do Oceano Atlântico no Número de Dias de Chuva no Estado do Mato Grosso do Sul a partir do estudo da sua dispersão, correlação, medidas de tendência central e de variação dos valores.

\section{MATERIAL E MÉTODOS}

\subsection{Caracterização da área de estudo}




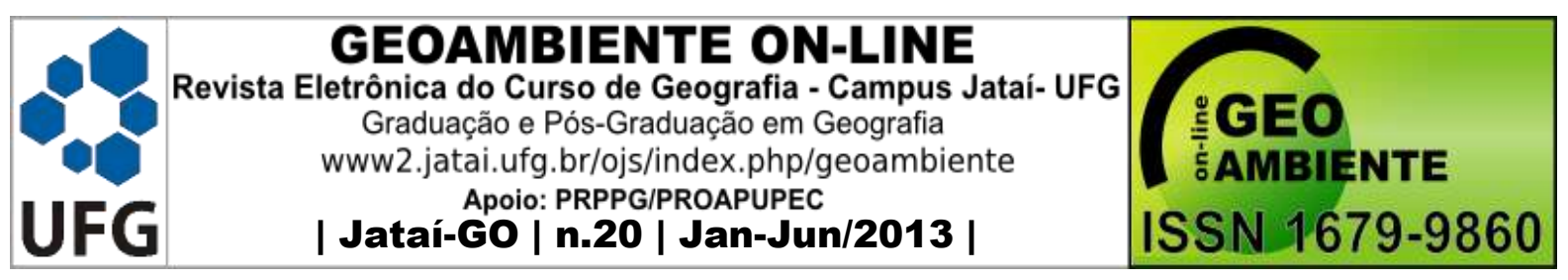

O Estado de Mato Grosso do Sul (Figura 1) está localizada na região centro-oeste do Brasil. O Estado de Mato Grosso do Sul possui uma área total de $357.124,33 \mathrm{~km}^{2}$ e perímetro de 3.663,36 km e possui 78 municípios sendo que o maior território municipal do Estado pertence ao município de Corumbá (área de $64.923,23 \mathrm{~km}^{2}$ e perímetro de $1.812,74 \mathrm{~km}$ ) e o menor, o município de Douradina (área de $278,94 \mathrm{~km}^{2}$ e perímetro de 75,94 km).

Segundo dados do IBGE (2010), toda a população residente nos municípios do Estado de Mato Grosso do Sul somam 2.449.024 pessoas, sendo que a maior densidade populacional pertence ao município de Campo Grande, com 97,22 habitantes $\left(\mathrm{km}^{2}\right)^{-1}$ (Figura 1).

Figura 1- Densidade de habitantes por quilômetro quadrado, clima e localização no Estado de Mato Grosso do Sul.

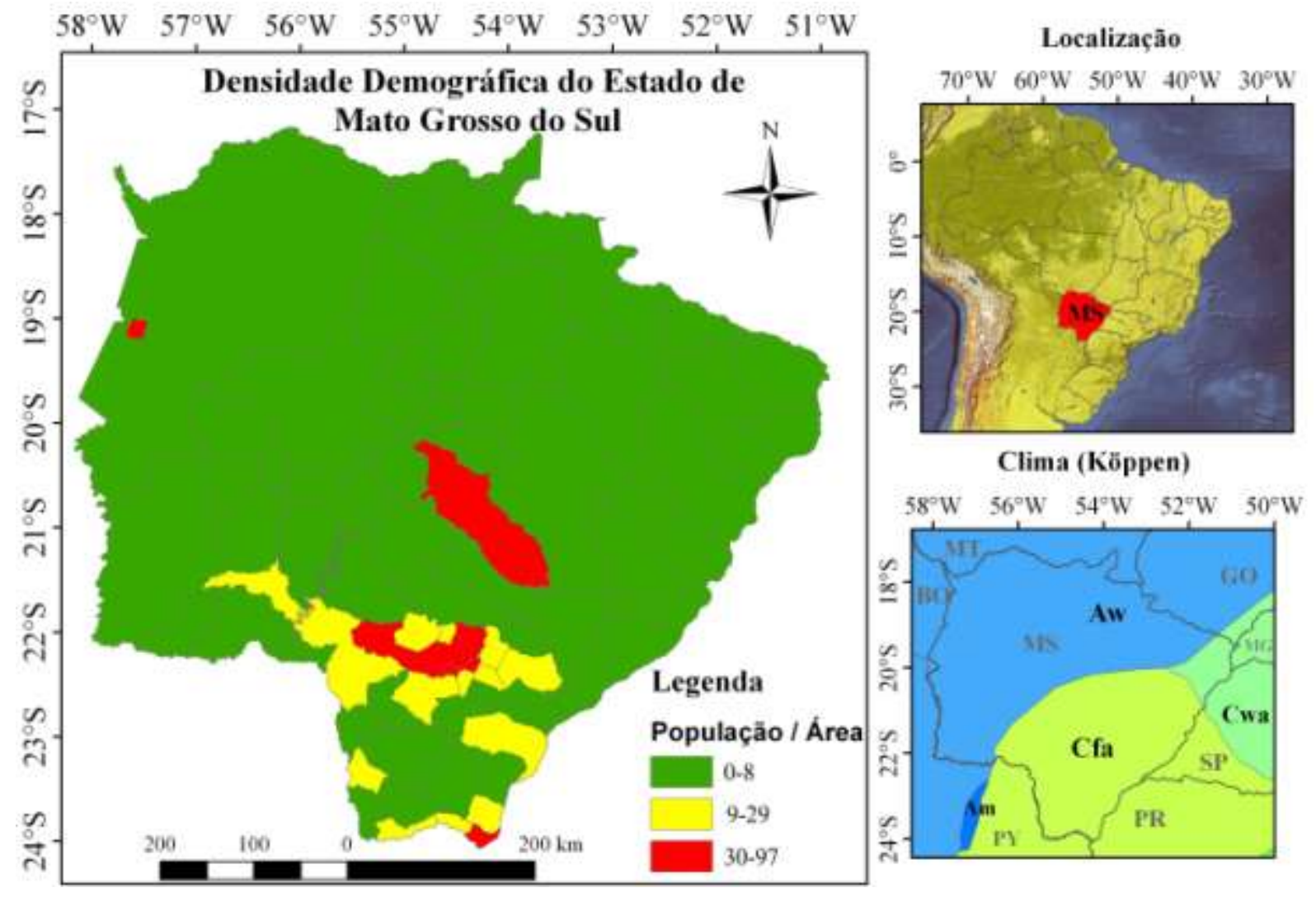

O clima do Estado de Mato Grosso do Sul, segundo a classificação de Köppen, ao norte e oeste é o tropical (Aw), com estação seca no inverno, ao sul e sudoeste é o subtropical úmido com verão quente ( $\mathrm{Cfa}$ ) e a leste é o subtropical úmido com inverno seco e verão úmido (Cwa) (Figura 1) (Peel et al., 2007). 


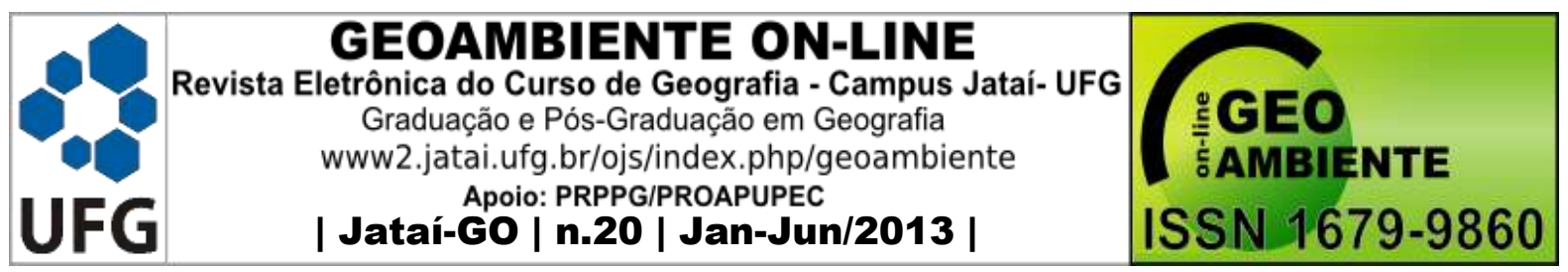

Neste trabalho foram utilizados dados do projeto SRTM (Shuttle Radar Topographic Mission) do qual foram obtidos imagens com resolução de 90 metros as quais foram agrupadas em um programa GIS (Geographic Information System) e em seguida o MDE (Modelo Digital de Elevação) foi delimitado o que permitiu analisar a hipsometria do Estado de Mato Grosso do Sul. O Estado de Mato Grosso do Sul está inserido nos biomas Cerrado, Mata Atlântica e Pantanal (Figura 2). Segundo os dados extraídos por SRTM, a amplitude altimétrica do Estado de Mato Grosso do Sul varia de 26 a 1.052 metros, sendo que a região nordeste do Estado concentra as maiores altitudes (Figura 2).

Figura 2- Relevo, altimetria, localização e bioma do Estado do Mato Grosso do Sul.
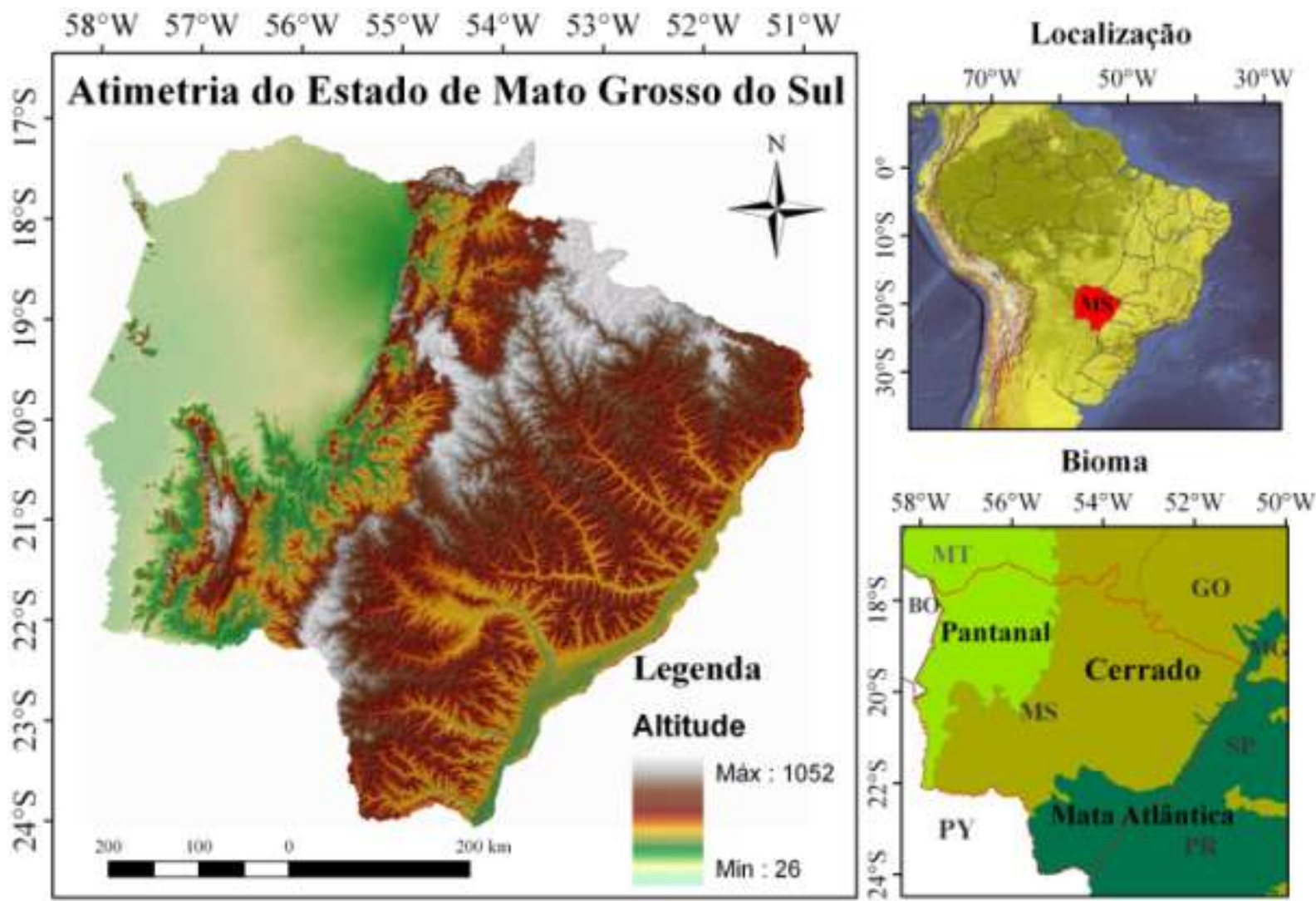

O uso do solo no Estado de Mato Grosso do Sul se concentra em grande parte na pecuária além de uma considerável região de vegetação remanescente (Figura 3). Utilizou-se neste estudo 92 estações pluviométricas (Figura 3), sendo 37 estações com 30 anos de dados e 55 estações com dados variando de 20 a 29 anos,cujos dados mensais do Número de Dias de Chuva utilizados neste estudo foram obtidos da Rede Hidrometeorológica Nacional da 


\begin{tabular}{|c|c|c|}
\hline & $\begin{array}{r}\text { GEOAMBIENTE } \\
\text { Revista Eletrônica do Curso de Geog } \\
\text { Graduacão e Pós-Graduacă } \\
\text { www2.jatai.ufg.br/ojs/index } \\
\text { Apoio: PRPPG/PROA } \\
\text { | Jataí-GO | n.20 | Ja }\end{array}$ & ISSN $1679-9860$ \\
\hline
\end{tabular}

Agência Nacional de Águas (ANA) e da CPRM/SGB (Companhia de Pesquisa de Recursos Minerais / Serviço Geológico do Brasil). Estes dados diários de NDC correspondem a uma série histórica de 25 anos (1982 a 2006) e foram compilados, consistidos, organizados e tratados estatisticamente, com informação diária, mensal, anual e sazonal.

A Temperatura da Superfície do Mar (TSM) é um índice que identifica as anomalias da superfície do oceano através de uma média móvel de três meses. Quando a variação TSM for maior que $0,0^{\circ} \mathrm{C}$ por no mínimo cinco meses consecutivos à variação TSM é denominada positiva, e quando variação TSM for menor que $0,0^{\circ} \mathrm{C}$ por no mínimo cinco meses consecutivos à variação TSM é denominada negativa. Assim variações TSM, para este estudo, é a diferença entre o valor momentâneo da temperatura das águas do Oceano Atlântico Sul e a temperatura considerada normal para aquele período. No Quadro 1 observa-se a intensidade da variação TSM no Oceano Atlântico Sul $\left(0-20^{\circ} \mathrm{Sul}, 30^{\circ}\right.$ Oeste, $10^{\circ}$ Leste $)$, que foram obtidos do Serviço Climatológico Nacional dos Estados Unidos (NOAA - National Weather Service).

Figura 3 - Uso e ocupação do solo, estações pluviométricas e localização do Estado de Mato Grosso do Sul.

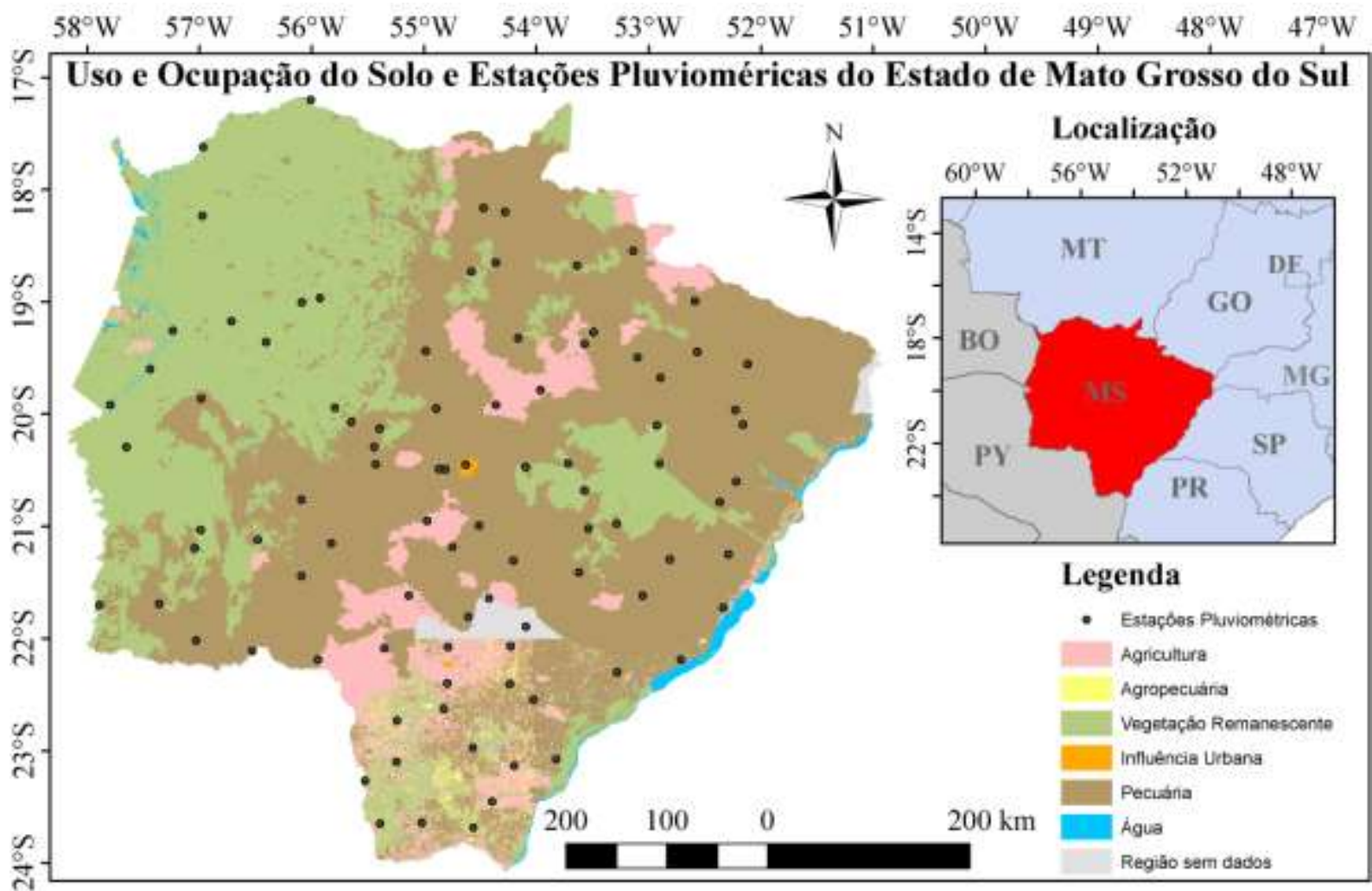




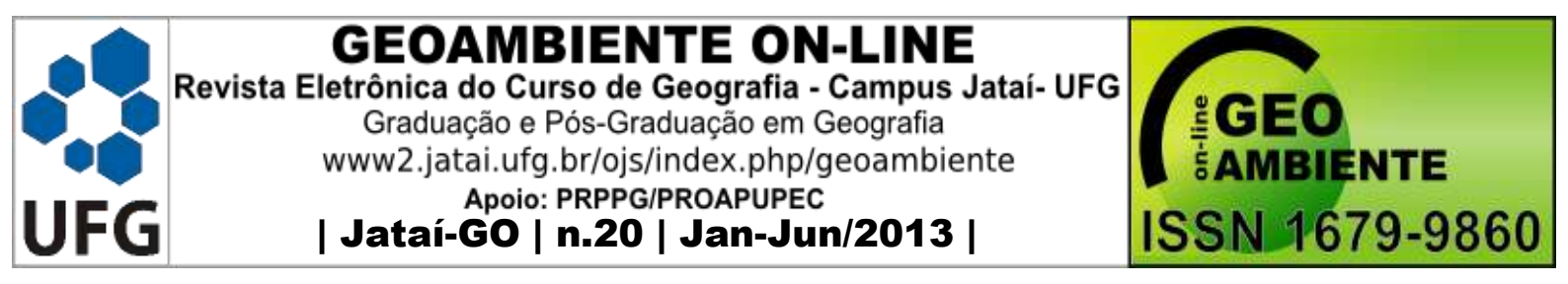

Quadro 1 - Variação TSM no Oceano Atlântico Sul para o período histórico estudado.

\begin{tabular}{|c|c|c|c|c|c|c|c|c|c|c|c|c|c|}
\hline \multirow{2}{*}{ Ano } & \multicolumn{12}{|c|}{ Variação TSM no Oceano Attântico Sul } & \multirow{2}{*}{ Média } \\
\hline & DJF & JFM & FMA & MAM & AMJ & MJJ & $\mathbf{J J A}$ & JAS & ASO & SON & OND & NDJ & \\
\hline 1982 & $-0,18$ & $-0,31$ & $-0,33$ & $-0,55$ & $-0,63$ & $-0,48$ & $-0,51$ & $-0,81$ & $-0,51$ & $-0,33$ & $-0,42$ & 0,34 & $-0,39$ \\
\hline 1983 & 0,09 & 0,09 & $-0,29$ & $-0,43$ & $-0,65$ & $-0,66$ & $-0,53$ & $-0,30$ & $-0,20$ & $-0,37$ & $-0,11$ & 0,15 & $-0,27$ \\
\hline 1984 & 0,37 & 0,41 & 0,40 & 0,22 & 0,10 & 0,34 & 0,30 & 0,59 & 0,62 & 0,38 & 0,20 & 0,16 & 0,34 \\
\hline 1985 & 0,21 & 0,25 & $-0,07$ & $-0,11$ & $-0,07$ & $-0,14$ & 0,02 & 0,07 & $-0,04$ & 0,09 & 0,13 & 0,01 & 0,03 \\
\hline 1986 & $-0,07$ & 0,18 & 0,09 & 0,01 & 0,09 & 0,19 & 0,05 & 0,13 & 0,14 & $-0,02$ & $-0,18$ & $-0,11$ & 0,04 \\
\hline 1987 & $-0,17$ & $-0,15$ & $-0,16$ & $-0,06$ & 0,09 & 0,18 & 0,24 & 0,15 & 0,13 & 0,22 & 0,46 & 0,17 & 0,09 \\
\hline 1988 & 0,49 & 0,25 & 0,42 & 0,37 & 0,49 & 0,53 & 0,41 & 0,34 & 0,12 & 0,15 & $-0,01$ & 0,07 & 0,30 \\
\hline 1989 & 0,46 & 0,16 & 0,15 & 0,14 & 0,18 & 0,15 & 0,14 & 0,33 & 0,15 & 0,12 & $-0,18$ & $-0,50$ & 0,11 \\
\hline 1990 & $-0,57$ & $-0,14$ & 0,04 & 0,11 & $-0,20$ & 0,06 & $-0,12$ & $-0,23$ & $-0,05$ & 0,07 & 0,06 & 0,11 & $-0,07$ \\
\hline 1991 & $-0,15$ & $-0,21$ & $-0,09$ & 0,07 & 0,31 & 0,10 & $-0,15$ & $-0,20$ & $-0,38$ & $-0,38$ & $-0,54$ & $-0,17$ & $-0,15$ \\
\hline 1992 & $-0,28$ & $-0,41$ & $-0,74$ & $-0,88$ & $-0,96$ & $-1,04$ & $-0,81$ & $-0,77$ & $-0,67$ & $-0,77$ & $-0,82$ & $-0,69$ & $-0,74$ \\
\hline 1993 & $-0,49$ & $-0,40$ & $-0,36$ & $-0,11$ & $-0,27$ & $-0,22$ & $-0,09$ & $-0,13$ & 0,41 & 0,42 & 0,58 & 0,46 & $-0,02$ \\
\hline 1994 & 0,10 & $-0,12$ & 0,06 & 0,14 & 0,08 & $-0,23$ & $-0,45$ & $-0,20$ & $-0,28$ & $-0,26$ & 0,03 & $-0,10$ & $-0,10$ \\
\hline 1995 & 0,01 & 0,28 & 0,50 & 0,53 & 0,38 & 0,39 & 0,16 & $-0,13$ & $-0,17$ & $-0,21$ & $-0,16$ & $-0,21$ & 0,11 \\
\hline 1996 & $-0,03$ & 0,26 & 0,16 & 0,41 & 0,48 & 0,53 & 0,45 & 0,30 & 0,10 & $-0,07$ & $-0,21$ & $-0,44$ & 0,16 \\
\hline 1997 & $-0,08$ & $-0,82$ & $-0,87$ & $-0,99$ & $-0,98$ & $-0,92$ & $-0,60$ & $-0,40$ & $-0,13$ & 0,37 & 0,67 & 0,82 & $-0,33$ \\
\hline 1998 & 0,73 & 0,43 & 0,27 & 0,27 & 0,28 & 0,36 & 0,49 & 0,13 & 0,12 & $-0,02$ & 0,14 & $-0,16$ & 0,25 \\
\hline 1999 & $-0,35$ & $-0,27$ & $-0,13$ & 0,21 & 0,23 & 0,17 & 0,42 & 0,24 & 0,04 & 0,07 & 0,03 & 0,19 & 0,07 \\
\hline 2000 & $-0,01$ & 0,14 & $-0,05$ & 0,04 & 0,07 & 0,02 & $-0,07$ & 0,10 & $-0,01$ & 0,00 & $-0,08$ & $-0,28$ & $-0,01$ \\
\hline 2001 & $-0,19$ & $-0,29$ & $-0,15$ & 0,01 & 0,27 & 0,13 & $-0,08$ & $-0,08$ & $-0,19$ & $-0,06$ & $-0,10$ & $-0,34$ & $-0,09$ \\
\hline 2002 & $-0,35$ & $-0,48$ & $-0,18$ & 0,09 & 0,22 & $-0,02$ & $-0,13$ & $-0,21$ & $-0,26$ & $-0,12$ & $-0,37$ & $-0,06$ & $-0,16$ \\
\hline 2003 & 0,15 & 0,32 & 0,36 & 0,15 & 0,01 & $-0,09$ & 0,31 & 0,49 & 0,38 & 0,37 & 0,42 & 0,42 & 0,27 \\
\hline 2004 & 0,20 & $-0,13$ & $-0,41$ & $-0,62$ & $-0,48$ & $-0,36$ & $-0,09$ & 0,08 & 0,18 & $-0,18$ & $-0,07$ & 0,17 & $-0,14$ \\
\hline 2005 & 0,44 & 0,45 & 0,29 & $-0,09$ & $-0,35$ & $-0,53$ & $-0,32$ & $-0,11$ & $-0,09$ & $-0,04$ & $-0,09$ & $-0,15$ & $-0,05$ \\
\hline 2006 & $-0,22$ & 0,10 & 0,25 & 0,16 & 0,22 & 0,38 & 0,33 & 0,23 & 0,18 & 0,07 & 0,03 & 0,10 & 0,15 \\
\hline
\end{tabular}

\subsection{Regressão linear e polinomial}

São métodos para se estimar a condicional de uma variável $Y$, dados os valores de algumas outras variáveis $X$. A regressão, em geral, trata da questão de se estimar um valor condicional esperado. Em muitas situações, uma relação linear pode ser válida para sumarizar a associação entre as variáveis $Y$ e $X$. Já a regressão polinomial tende a descrever o caminhamento da evolução da variável dependente $Y$ conforme as modificações da variável $X$. A regressão linear e polinomial é, respectivamente, descrita como: 


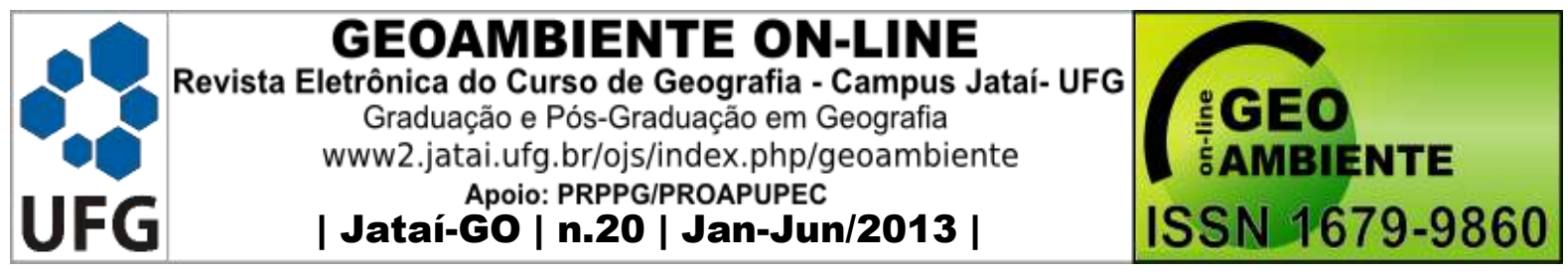

$\mathrm{Y}=\beta_{0}+\beta_{1} \mathrm{X}$

$Y=\beta_{6} X^{6}+\beta_{5} X^{5}+\cdots+\beta_{1} X+\beta_{0}$

em que, $Y$ é a variável linear dependente; $\beta_{6}, \beta_{5}, \ldots, \beta_{1}$, e $\beta_{0}$ são os coeficientes da regressão; $X$ é a variável independente.

\section{Verificação estatística descritiva}

Através da estatística descritiva, podemos ter características essenciais para a formação de histograma de frequiências relativas de uma amostra de dados hidrológicos (Naghettini \& Pinto, 2007). Para este estudo foram calculadas as seguintes medidas de tendência central e de dispersão.

\section{- Medidas de tendências centrais}

A média é a medida de posição mais freqüentemente usada e tem um significado teórico importante na estimativa de amostras. É calculada pela seguinte fórmula:

$\mathrm{X}=\frac{\mathrm{X}_{1}, \ldots, \mathrm{X}_{\mathrm{n}}}{\mathrm{N}}=\frac{1}{\mathrm{~N}} \sum_{\mathrm{i}=1}^{\mathrm{N}} \mathrm{X}_{1}$

em que, $X$ - é a média; $N$ - tamanho da amostra; $X_{1}$ até $X_{n}$ - somatórios da amostra.

A mediana é outra medida de posição mais resistente do que a média, por ser imune á eventual presença de valores extremos discordantes na amostra. É calculada pela equação:

$X_{\text {med }}=\frac{X_{\left(\frac{N}{2}\right)}+X_{\left(\frac{N}{2}+1\right)}}{2}$

em que, $\mathrm{N}$ - tamanho da amostra; $\mathrm{X}$ - posições das amostras.

\section{- Medidas de dispersão}

O desvio padrão é fortemente influenciado pelos menores e maiores desvios, constituindo-se na medida de dispersão mais frequentemente usada. É calculado pela seguinte expressão:

$\mathrm{S}=\sqrt{\frac{1}{\mathrm{~N}-1} \sum_{\mathrm{I}=1}^{\mathrm{N}}\left(\mathrm{X}_{1}-\mathrm{X}\right)^{2}}$

em que, $N$ - tamanho da amostra; $X_{i}$ - valor de cada amostra; $\bar{X}$ - média.

Utilizando-se as medidas de tendência central e de dispersão podem-se verificar analiticamente os parâmetros, e observar se as amostras são diferentes ou semelhantes. 


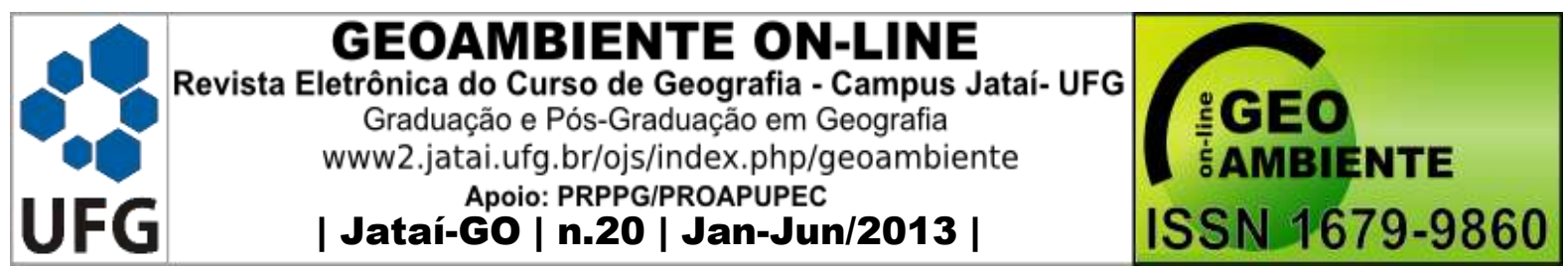

\section{RESULTADOS E DISCUSSÃO}

No Estado de Mato Grosso do Sul observa-se para o mês de janeiro (Figura 4) um decréscimo do NDC durante os episódios de variação TSM negativa do Oceano Atlântico Sul, enquanto durante os episódios de variação positiva de TSM não se observa variação do NDC. A variação TSM negativa mais intensa para os meses de janeiro de 1982 a 2006 foi de $-0,6^{\circ} \mathrm{C}$ (1990), ocasionando 15 dias de chuva, enquanto que a mais intensa variação TSM positiva foi de $0,7^{\circ} \mathrm{C}$ (1998) e ocasionou 9 dias de chuva. O maior NDC observado foi de 20 dias (1989), para um valor de variação TSM de $0,5^{\circ} \mathrm{C}$. O menor NDC (9 dias) ocorreu nos anos de 1992, 1998 e 2004, os quais estavam sob influência de variações TSM de $-0,3^{\circ} \mathrm{C}, 0,7^{\circ} \mathrm{C}$ e $0,2^{\circ} \mathrm{C}$, respectivamente.

Figura 4 - Dispersão em janeiro do Número de Dias de Chuva em relação à variação TSM Atlântico Sul do período.

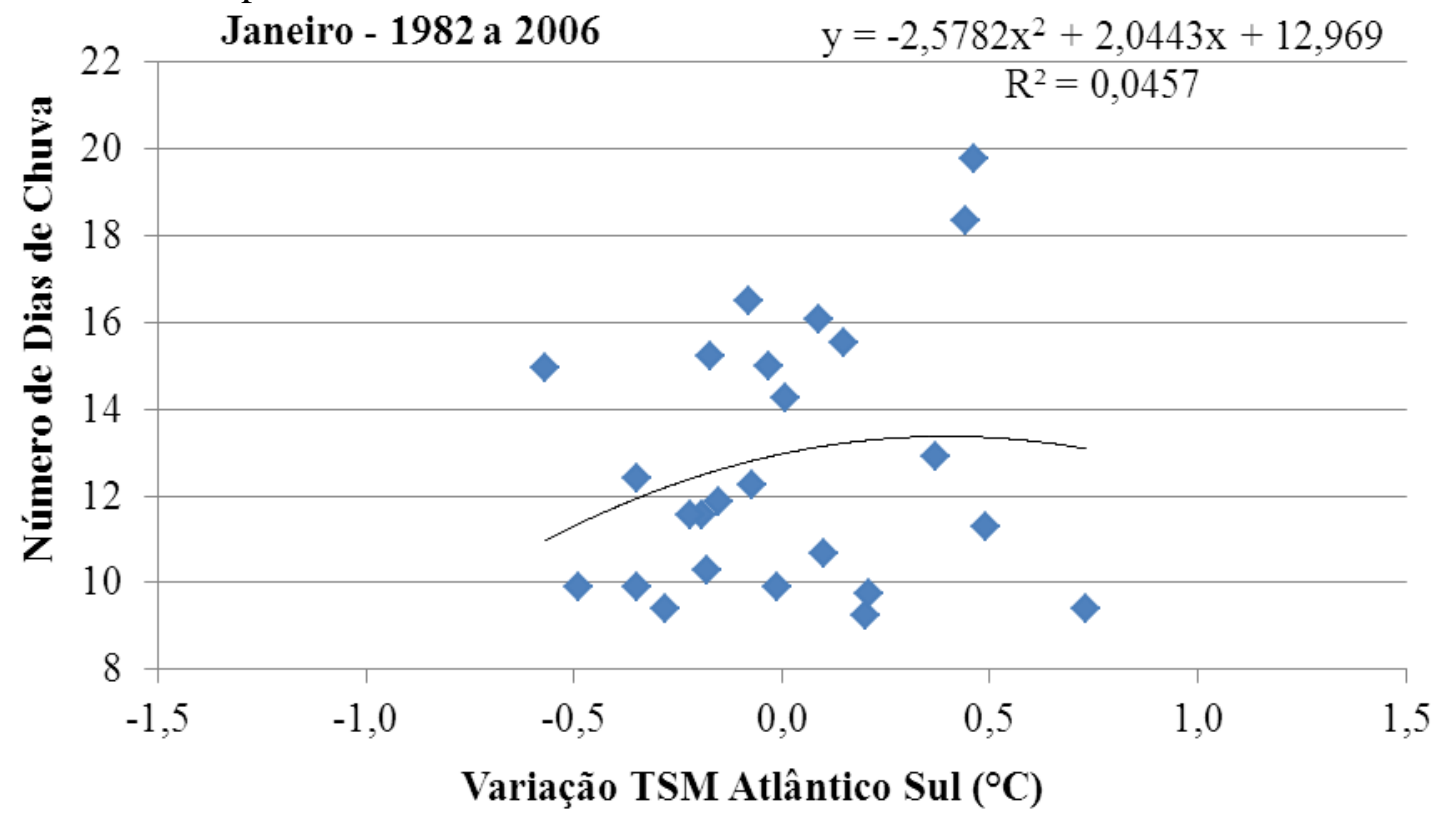

No mês de fevereiro (Figura 5) constata-se um decréscimo pouco significativo do NDC tanto na ocorrência de variações TSM positiva quanto nas variações TSM negativa. O mês de fevereiro do ano de 2005 esteve sob influência da maior variação TSM positiva para este mês $\left(0,5^{\circ} \mathrm{C}\right)$ e apresentou o menor NDC da série histórica para este mês ( 5 dias); contudo o maior NDC (15 dias) aconteceu sob influência da segunda menor variação TSM positiva $\left(0,2^{\circ} \mathrm{C}\right)$, no ano de 1989 . Na maior variação TSM negativa $\left(-0,8^{\circ} \mathrm{C}\right)$ registrou-se 11 dias de chuva (1997). 


\begin{tabular}{|c|c|c|}
\hline & $\begin{array}{r}\text { GEOAMBIENTE } \\
\text { Revista Eletrônica do Curso de Geog } \\
\text { Graduacão e Pós-Graduacă } \\
\text { www2.jatai.ufg.br/ojs/index } \\
\text { Apoio: PRPPG/PROA } \\
\text { | Jataí-GO | n.20 | Ja }\end{array}$ & ISSN $1679-9860$ \\
\hline
\end{tabular}

Figura 5- Dispersão em fevereiro do Número de Dias de Chuva em relação à variação TSM Atlântico Sul do período.

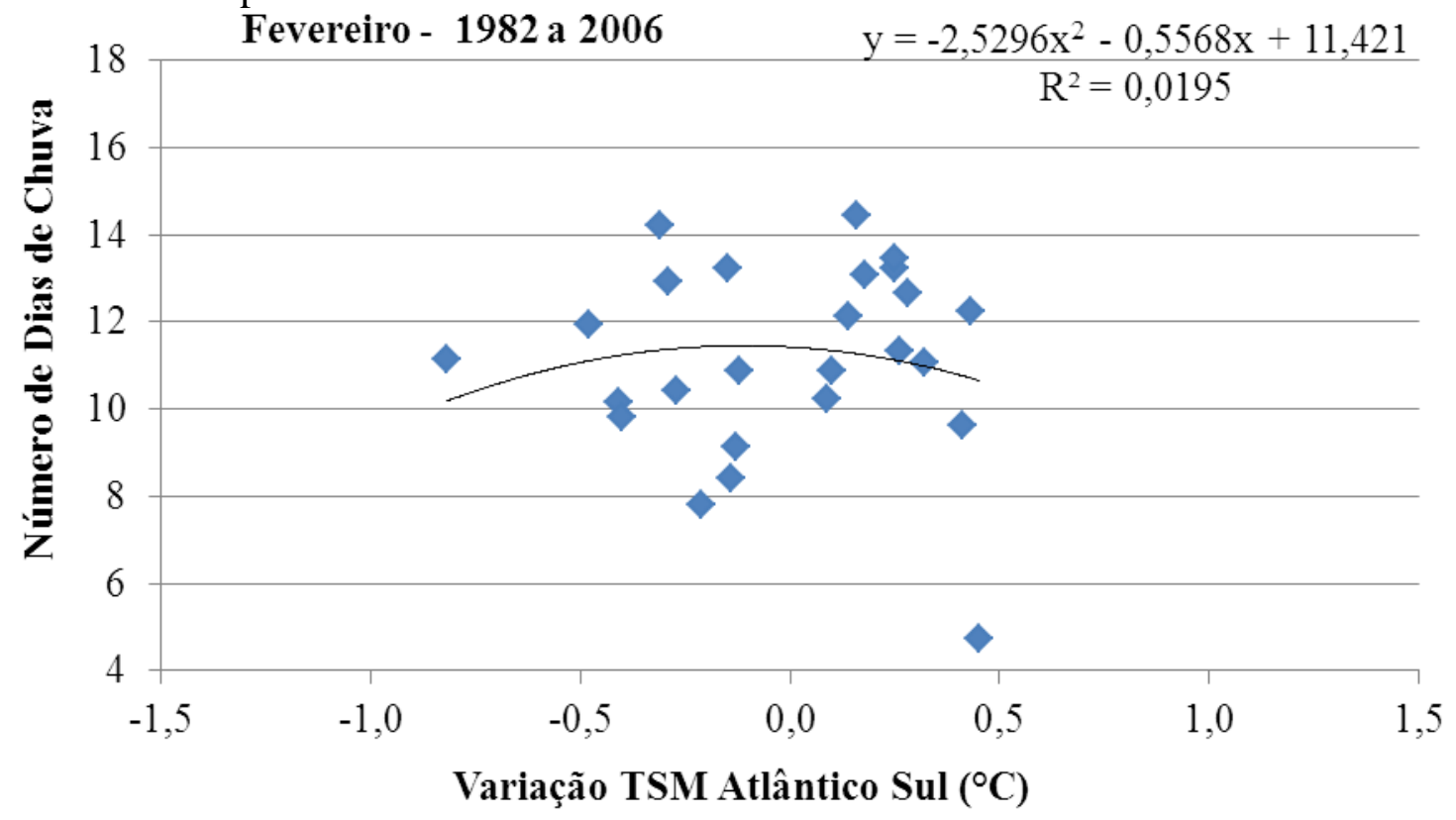

Para o mês de março (Figura 6) observa-se um decréscimo do NDC na ocorrência de variações TSM negativa do Atlântico Sul, já as variações TSM positivas não interferiram no NDC deste mês. As variações TSM variaram entre $-0,9^{\circ} \mathrm{C}$ e $0,5^{\circ} \mathrm{C}$. A maior variação TSM negativa provocou um total de 7 dias de chuva (1997), enquanto que a maior variação TSM positiva provocou um total de 8 dias de chuva (1995). O ano de 1982 apresentou o mês de março da série histórica com o maior NDC (15 dias) período no qual a variação TSM foi de $-0,3^{\circ} \mathrm{C}$. O menor NDC para este mês foi de 6 dias nos anos de 2004 e 2005, sob variação TSM de $-0,4^{\circ} \mathrm{C}$ e $0,3^{\circ} \mathrm{C}$, respectivamente.

No mês de abril (Figura 7) houve um acréscimo pouco significativo do NDC. Mais da metade dos meses de abril da série histórica esteve sob influência de variações TSM positiva, contudo foi neste mês que aconteceu um dos maiores resfriamento das águas do Oceano Atlântico Sul $\left(-1,0^{\circ} \mathrm{C}\right)$, que acarretou em 6 dias de chuva no ano de 1997. A maior variação TSM positiva para este mês $\left(0,5^{\circ} \mathrm{C}\right)$ aconteceu em 1995 e provocou 5 dias de chuva. O maior NDC (10 dias) e o menor NDC (3 dias) aconteceram durante episódios de variações TSM positiva, $0,4^{\circ} \mathrm{C}(1988)$ e $0,1^{\circ} \mathrm{C}(2002)$, respectivamente. 


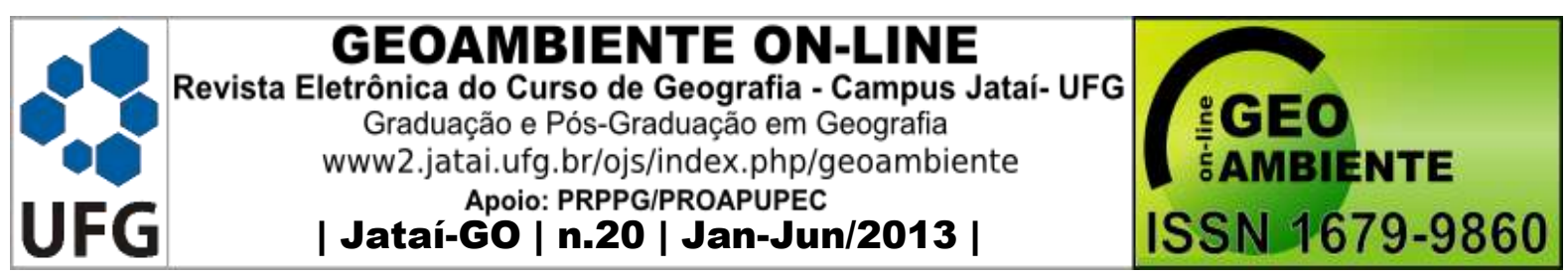

Figura 6 - Dispersão em março do Número de Dias de Chuva em relação à variação TSM Atlântico Sul do período.

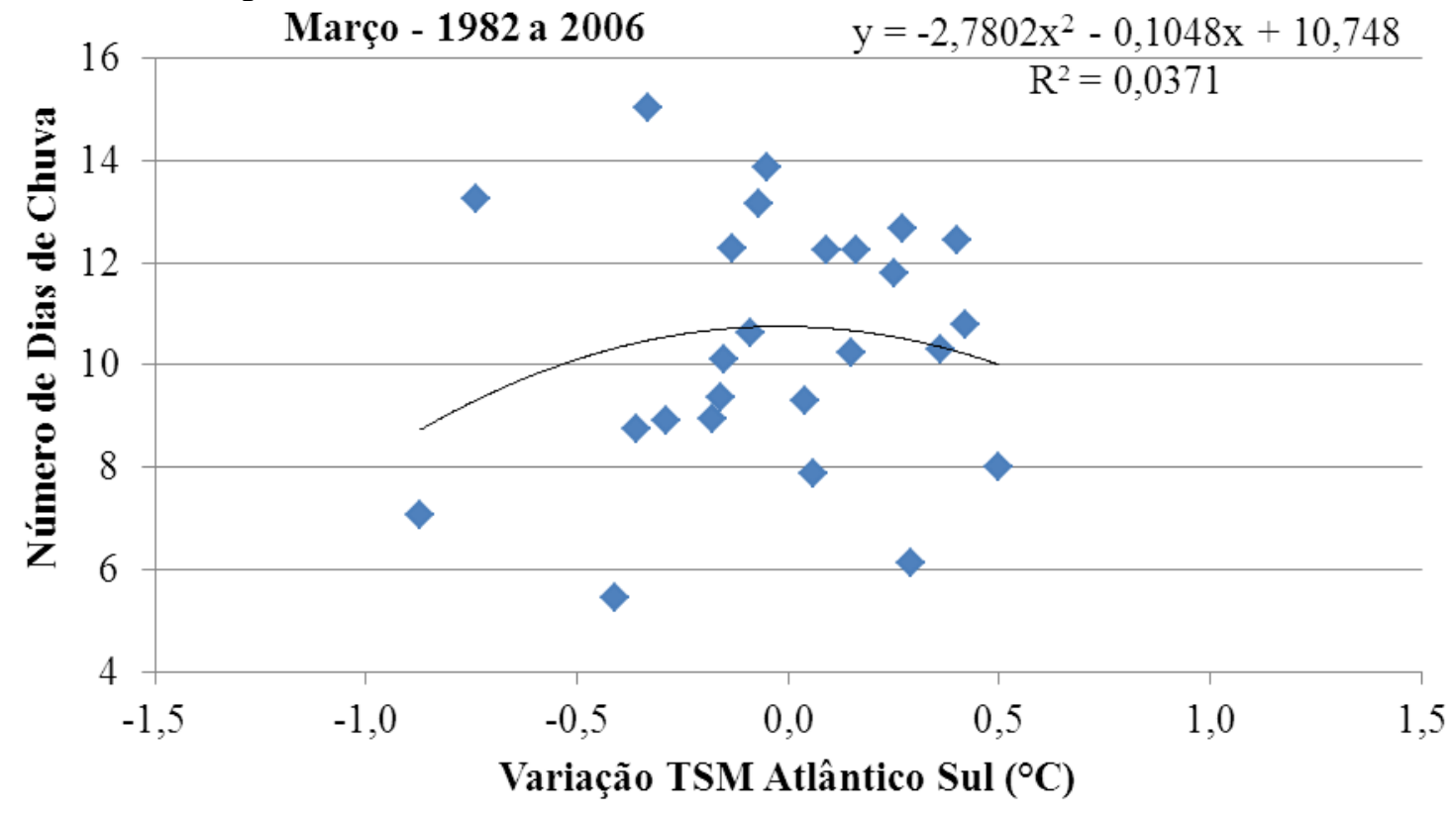

Figura 7 - Dispersão em abril do Número de Dias de Chuva em relação à variação TSM Atlântico Sul do período

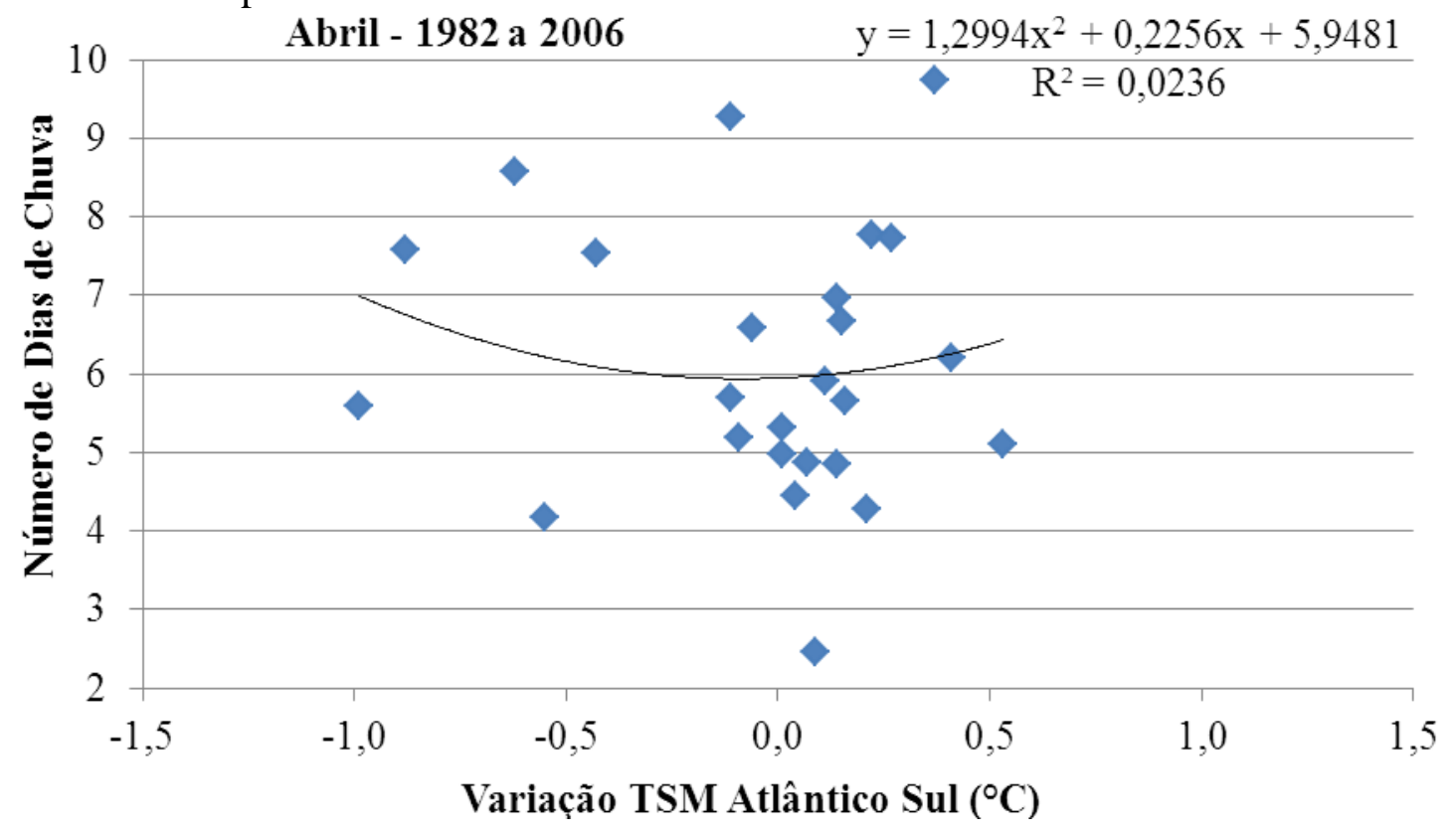

A variação TSM positiva mais intensa para o mês de maio (Figura 8 ) foi de $0,5^{\circ} \mathrm{C}$ nos anos de 1988 (7 dias de chuva) e 1996 (6 dias de chuva) caracterizando um pequeno decréscimo do NDC durante sua ocorrência. O oposto acontece nos episódios de variação 


\begin{tabular}{|c|c|c|}
\hline & $\begin{array}{r}\text { GEOAMBIENTE } \\
\text { Revista Eletrônica do Curso de Geog } \\
\text { Graduacão e Pós-Graduacă } \\
\text { www2.jatai.ufg.br/ojs/index } \\
\text { Apoio: PRPPG/PROA } \\
\text { | Jataí-GO | n.20 | Ja }\end{array}$ & ISSN $1679-9860$ \\
\hline
\end{tabular}

TSM negativa quando se detecta um aumento do NDC, a qual em sua ocorrência mais intensa $\left(-1,0^{\circ} \mathrm{C}\right)$ ocasionou 7 dias de chuva no ano de 1992 e 4 dias de chuva no ano de 1997. O maior NDC (11 dias) foi observado durante uma variação TSM negativa de $-0,5^{\circ} \mathrm{C}$ no ano de 2004 . O menor NDC ( 2 dias) estava sob influência de uma variação TSM positiva de $0,2^{\circ} \mathrm{C}$ no ano de 1999.

Figura 8 - Dispersão em maio do Número de Dias de Chuva em relação à variação TSM Atlântico Sul do período.

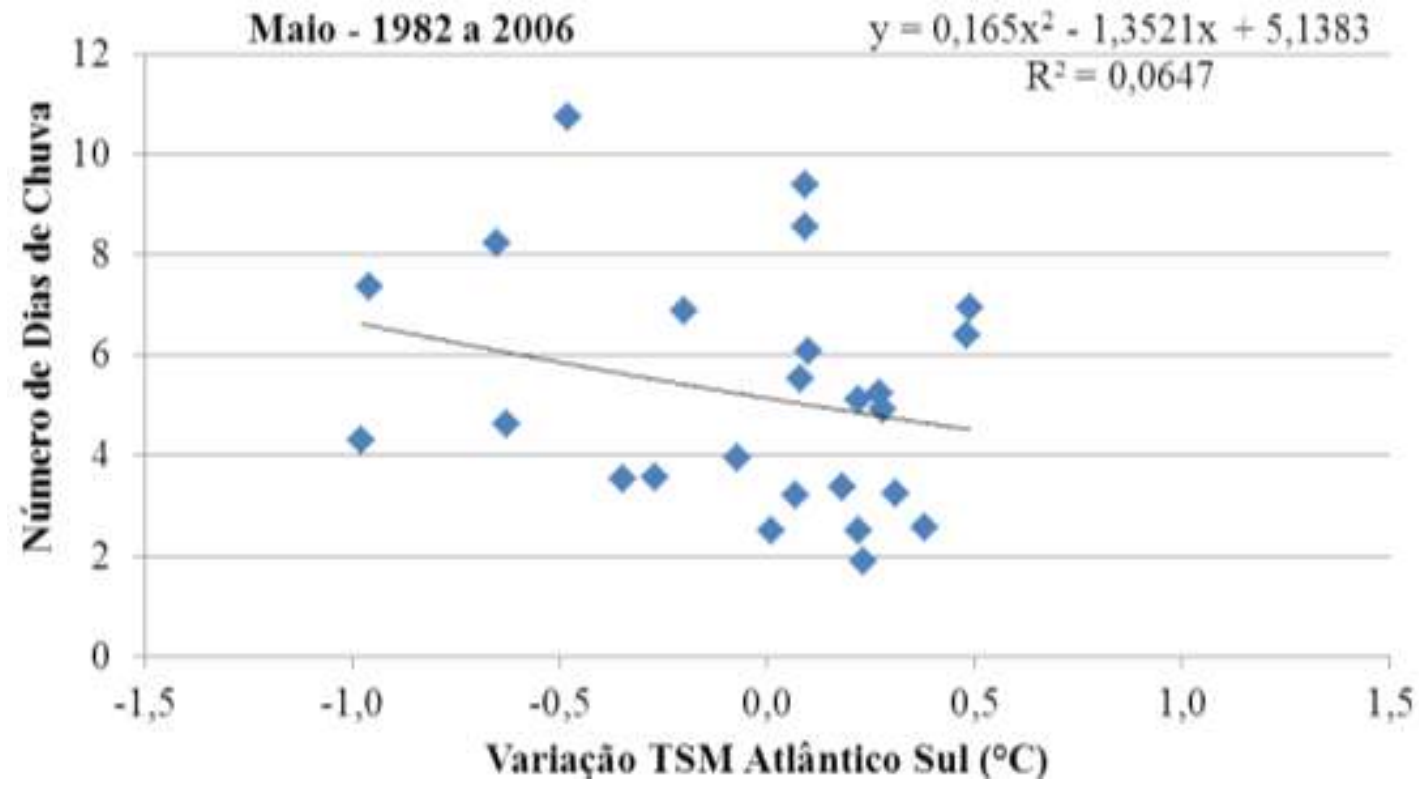

No mês de junho (Figura 9) aconteceu algo semelhante ao mês de maio, já que em ambos as variações TSM positivas caracterizaram um pequeno decréscimo do NDC, enquanto durante as variações TSM negativas observou-se um aumento do NDC. Pode-se observar que as variações TSM nas águas do Oceano Atlântico Sul variaram de $-1,0^{\circ} \mathrm{C}$ a $0,5^{\circ} \mathrm{C}$ nos meses de junho dos anos de 1982 a 2006. O mês de junho do ano 2002 não registrou variação TSM das águas do Oceano Atlântico Sul e também não choveu no Estado de Mato Grosso Sul. O maior NDC foi de 8 dias sob variação TSM de $-0,9^{\circ} \mathrm{C}$ no ano de 1997 . A mais intensa variação TSM negativa $\left(-1,0^{\circ} \mathrm{C}\right)$ causou 3 dias de chuva no ano de 1992 , enquanto que a mais intensa variação TSM positiva $\left(0,5^{\circ} \mathrm{C}\right)$ ocasionou 4 dias de chuva em 1988 e 2 dias de chuva em 1996. 


\begin{tabular}{|c|c|c|}
\hline & $\begin{array}{r}\text { GEOAMBIENTE } \\
\text { Revista Eletrônica do Curso de Geog } \\
\text { Graduacão e Pós-Graduacă } \\
\text { www2.jatai.ufg.br/ojs/index } \\
\text { Apoio: PRPPG/PROA } \\
\text { | Jataí-GO | n.20 | Ja }\end{array}$ & ISSN $1679-9860$ \\
\hline
\end{tabular}

Figura 9 - Dispersão em junho do Número de Dias de Chuva em relação à variação TSM Atlântico Sul do período.

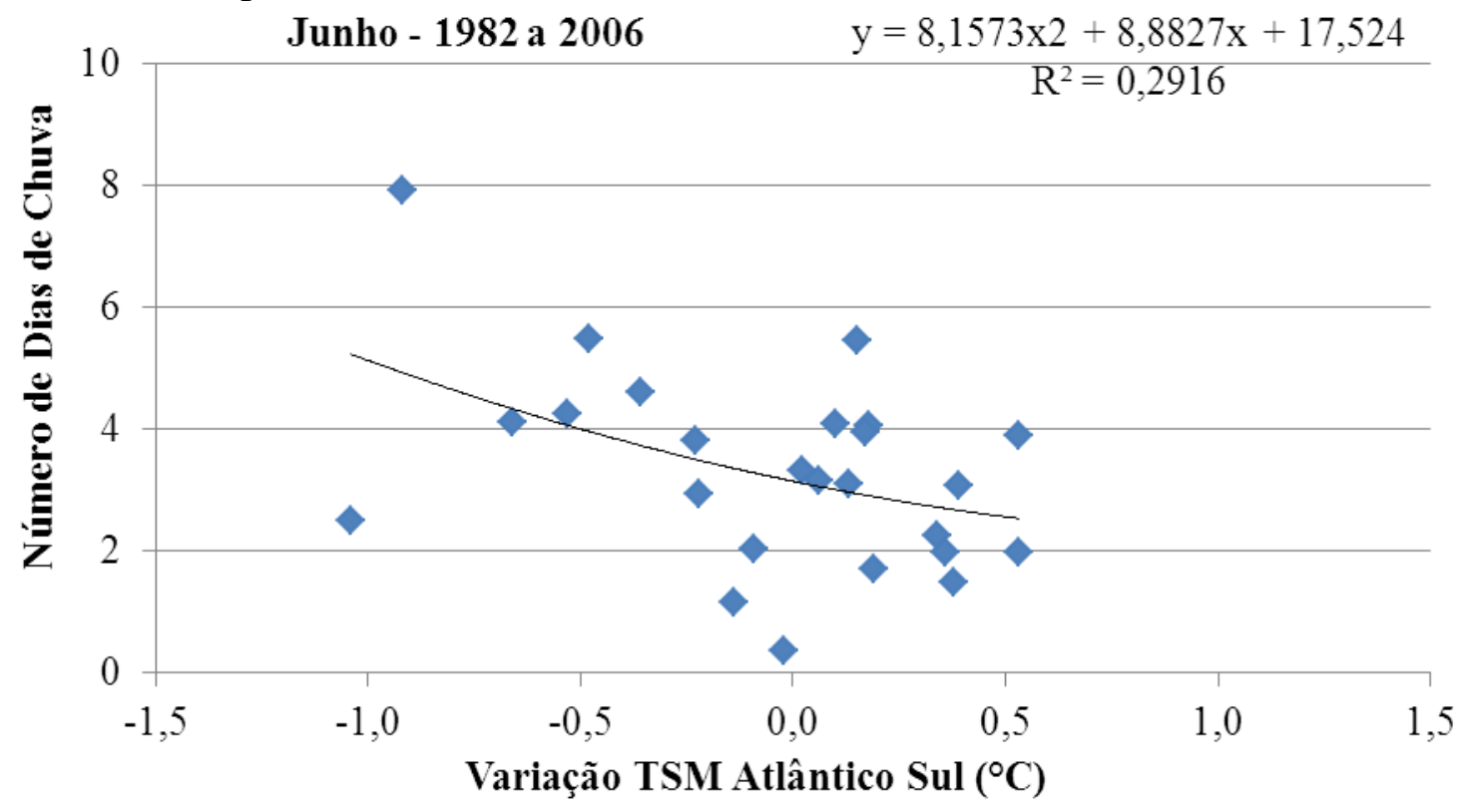

No mês de julho (Figura 10) as relações entre variações TSM e dias de chuva foram inversamente proporcionais, enquanto as intensidades das variações TSM aumentaram os dias de chuva diminuíram. O maior NDC registrado para este mês na série histórica foi 4 dias (1993) e estava sob influência de uma variação TSM de $-0,1^{\circ} \mathrm{C}$. Choveu 1 dia no mês de julho dos anos de 1984, 1988, 1996, 1997, 1998, 1999 e 2003, nos quais a variação TSM variou de $-0,6^{\circ} \mathrm{C}$ a $0,5^{\circ} \mathrm{C}$, incluindo assim a mais intensa variação TSM positiva do mês de julho. A maior variação TSM negativa foi $-0,8^{\circ} \mathrm{C}(1992)$ e provocou 3 dias de chuva no Estado de Mato Grosso do Sul.

Durante o mês de agosto (Figura 11) as variações TSM aconteceram com intensidades entre $-0,8^{\circ} \mathrm{C}$ e $0,6^{\circ} \mathrm{C}$ observando-se um acréscimo dos dias de chuva no Estado de Mato Grosso Sul, principalmente durante os episódios de variação TSM positiva. Na ocorrência da variação TSM negativa mais intensa registrou-se 3 e 4 dias de chuva, nos anos de 1982 e 1992, respectivamente; enquanto que a mais intensa variação TSM positiva ocorreu em 1984 ocasionando 5 dias de chuva. Em $1986\left(0,1^{\circ} \mathrm{C}\right)$ aconteceu o máximo NDC para o mês de agosto da série histórica ( 8 dias). Não foi registrado chuvas nos meses de agosto dos anos de $1983\left(-0,3^{\circ} \mathrm{C}\right), 1999\left(0,2^{\circ} \mathrm{C}\right)$ e $2004\left(0,1^{\circ} \mathrm{C}\right)$. 


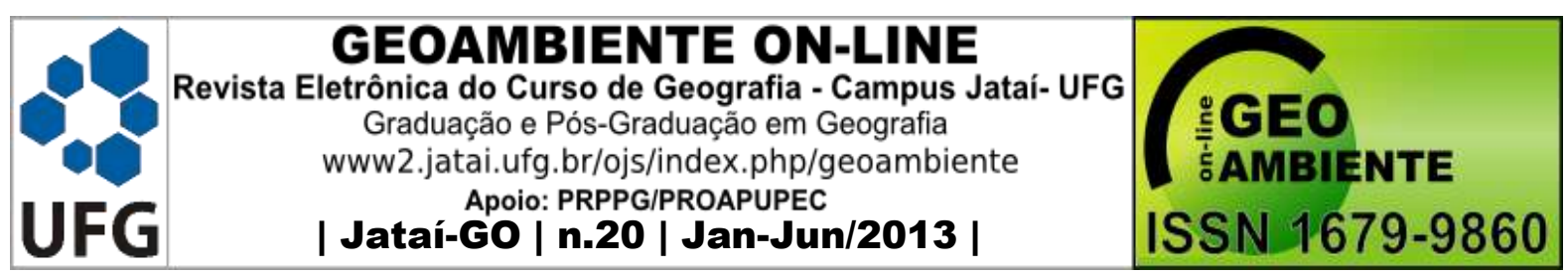

Figura 10 - Dispersão em julho do Número de Dias de Chuva em relação à variação TSM Atlântico Sul do período.

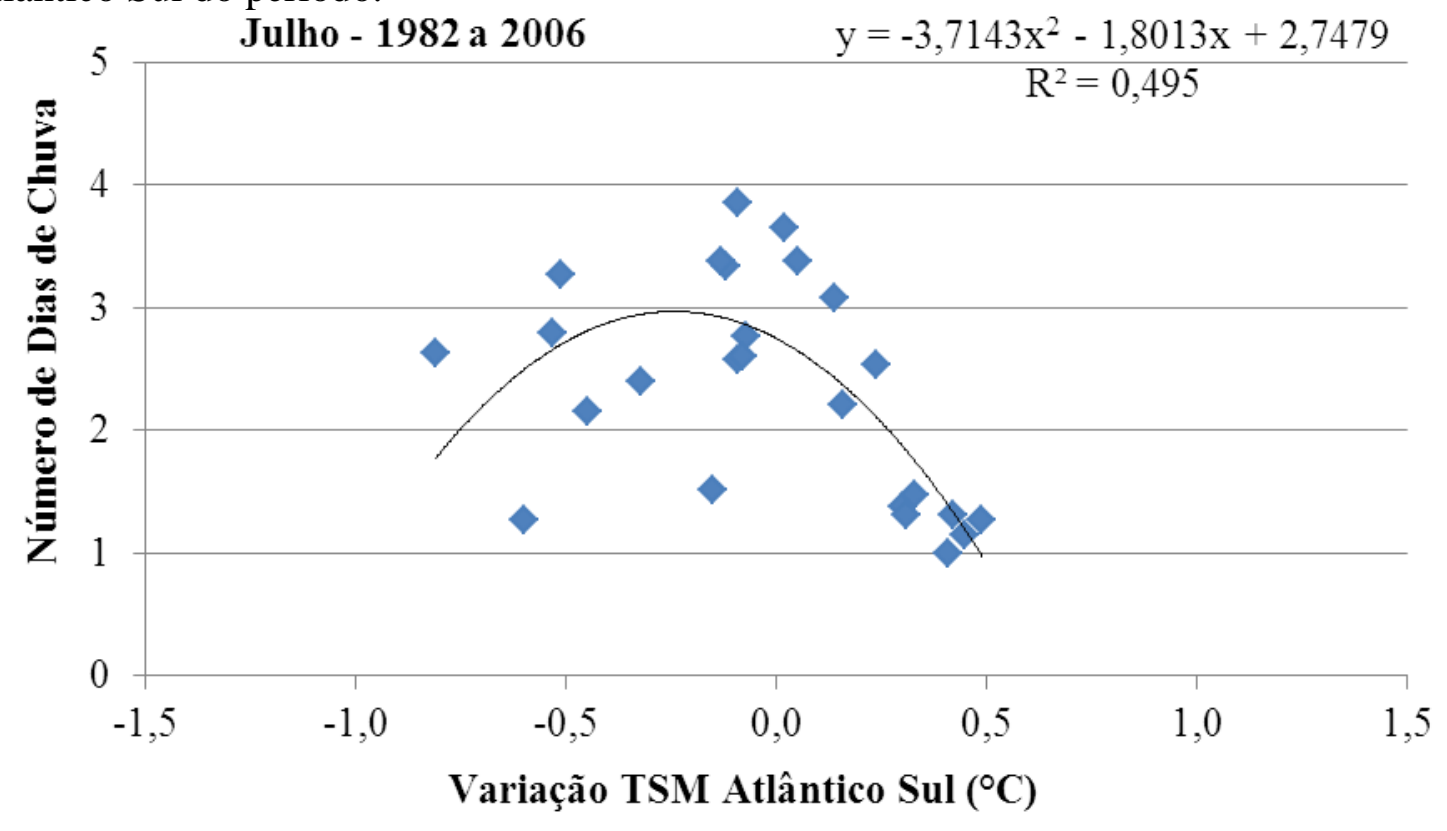

Figura 11 - Dispersão em agosto do Número de Dias de Chuva em relação à variação TSM Atlântico Sul do período.

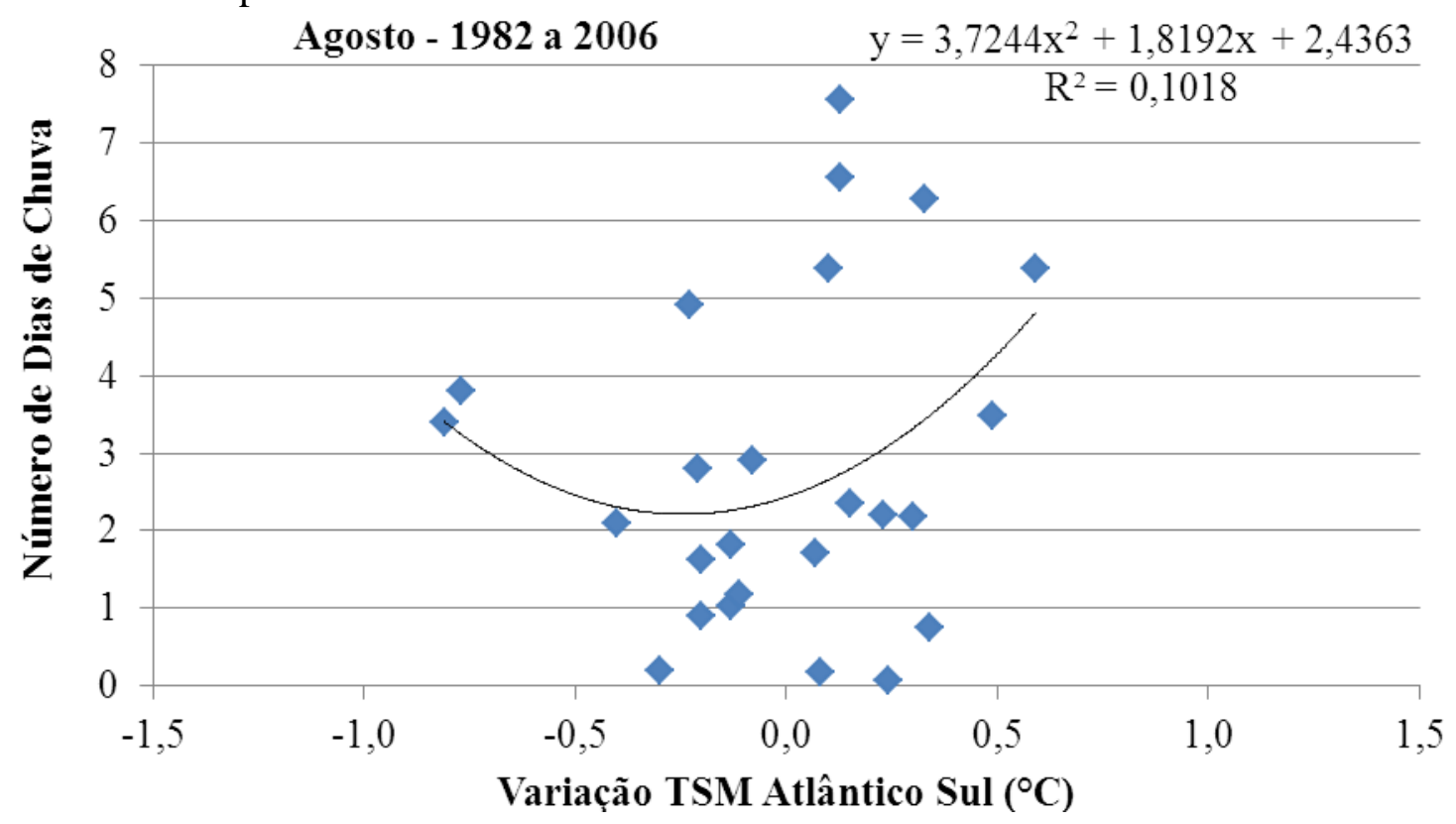

No mês de setembro (Figura 12) aconteceu algo parecido com o mês de agosto, porém o acréscimo dos dias de chuva foi maior nos períodos de variação TSM negativa. O menor NDC deste mês (2 dias) se deu durante pequenas variações TSM positiva no ano de 1988 $\left(0,1^{\circ} \mathrm{C}\right)$ e $2004\left(0,2^{\circ} \mathrm{C}\right)$. Já a variação TSM negativa em sua intensidade máxima $\left(-0,7^{\circ} \mathrm{C}\right)$ 


\begin{tabular}{|c|c|c|}
\hline & $\begin{array}{r}\text { GEOAMBIENTE } \\
\text { Revista Eletrônica do Curso de Geog } \\
\text { Graduacão e Pós-Graduacă } \\
\text { www2.jatai.ufg.br/ojs/index } \\
\text { Apoio: PRPPG/PROA } \\
\text { | Jataí-GO | n.20 | Ja }\end{array}$ & ISSN $1679-9860$ \\
\hline
\end{tabular}

ocasionou 10 dias de chuva (1992), que foi o maior NDC para este mês. No ano de 1984 registrou-se a maior variação TSM positiva $\left(0,6^{\circ} \mathrm{C}\right)$ que acarretou em 6 dias de chuva.

Figura 12 - Dispersão em setembro do Número de Dias de Chuva em relação à variação TSM Atlântico Sul do período.

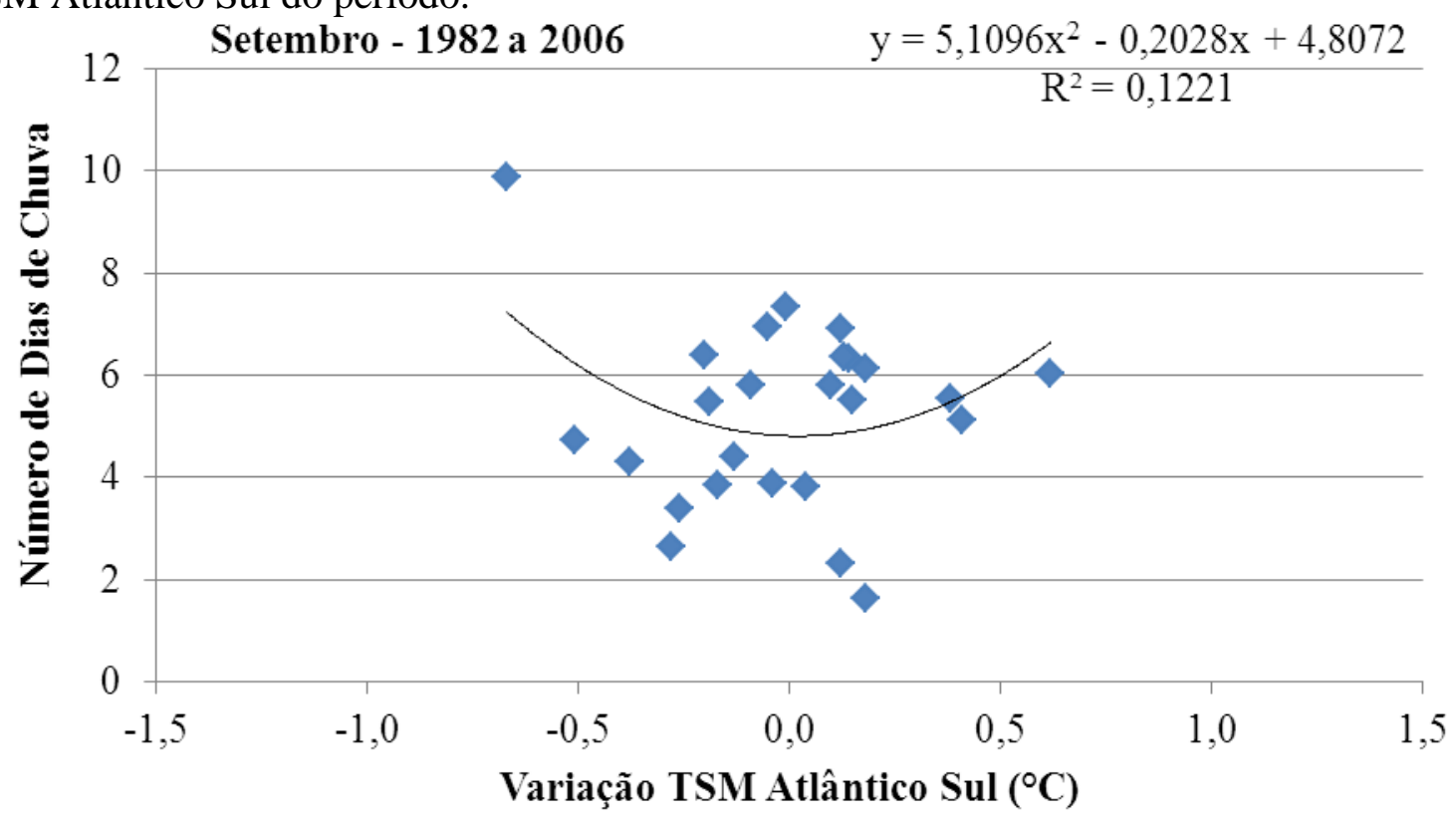

Durante o mês de outubro (Figura 13) as variações TSM das águas do Oceano Atlântico Sul ficaram entre $-0,8^{\circ} \mathrm{C}(1992)$ e $0,4^{\circ} \mathrm{C}(1984,1993,1997$ e 2003), mas a que mais interferiu no NDC no Estado de Mato Grosso do Sul foram às variações TSM negativas, observando-se um acréscimo do NDC durante suas ocorrências. O ano de 1984 não esteve sob influência de nenhuma variação TSM, no qual se deu o mês de outubro com maior NDC da série histórica, 10 dias. Choveu 5 dias (menor NDC) nos mês de outubro dos anos de 1984, 1986, 1989 e 1999 os quais estiveram sob influência de baixas variações TSM, assim como a maioria dos anos. A maior variação TSM negativa provocou 9 dias de chuva no mês de outubro do ano 1992.

No mês de novembro (Figura 14) as variações TSM tanto positiva quanto negativa não interferem no NDC, já que a linha de tendência se mantém quase linear. A mais intensa variação TSM negativa $\left(-0,8^{\circ} \mathrm{C}\right)$ proporcionou 9 dias de chuva em 1992. A mais intensa variação TSM positiva $\left(0,7^{\circ} \mathrm{C}\right)$ proporcionou o maior NDC do mês de novembro da série histórica, 12 dias com chuva em 1997.O mês de novembro de 1991 estava sob influência de uma variação negativa de $-0,5^{\circ} \mathrm{C}$ e foi o que apresentou o menor NDC (5 dias). 


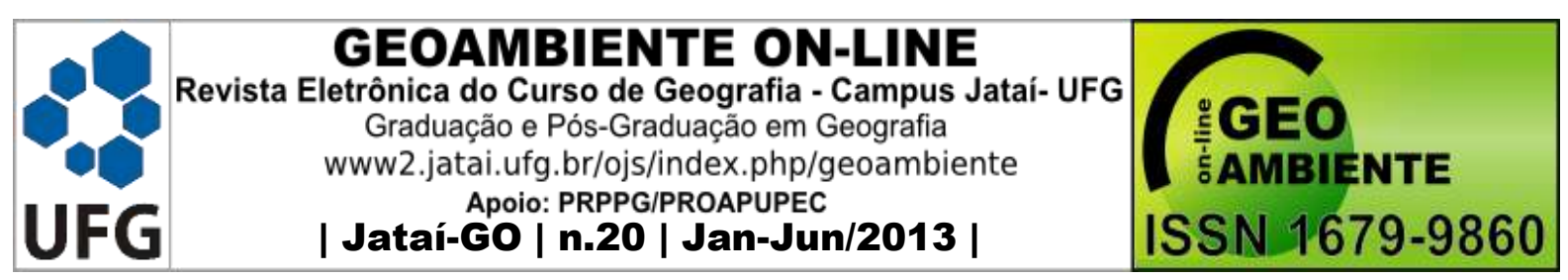

Figura 13 - Dispersão em outubro do Número de Dias de Chuva em relação à variação TSM Atlântico Sul do período.

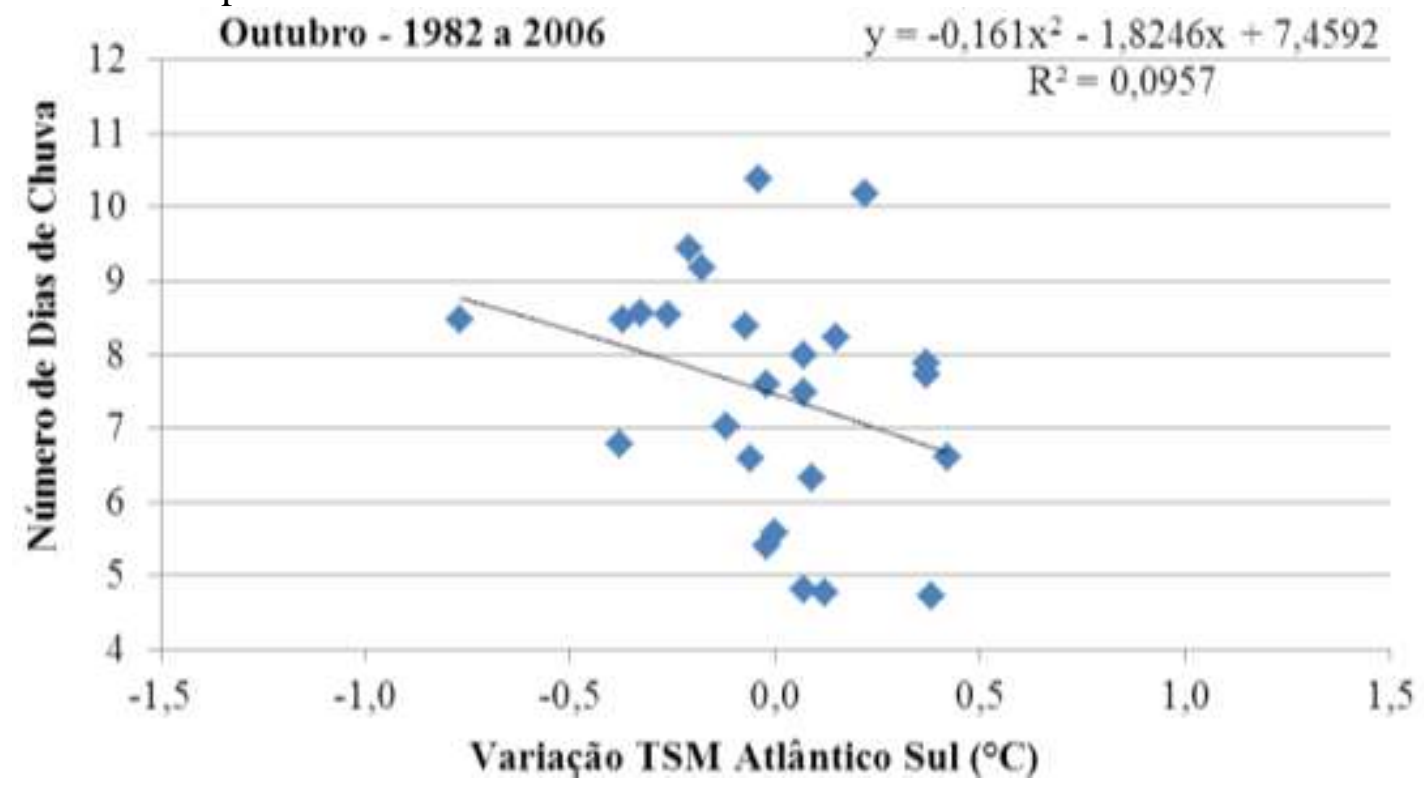

Figura 14 - Dispersão em novembro do Número de Dias de Chuva em relação à variação TSM Atlântico Sul do período.

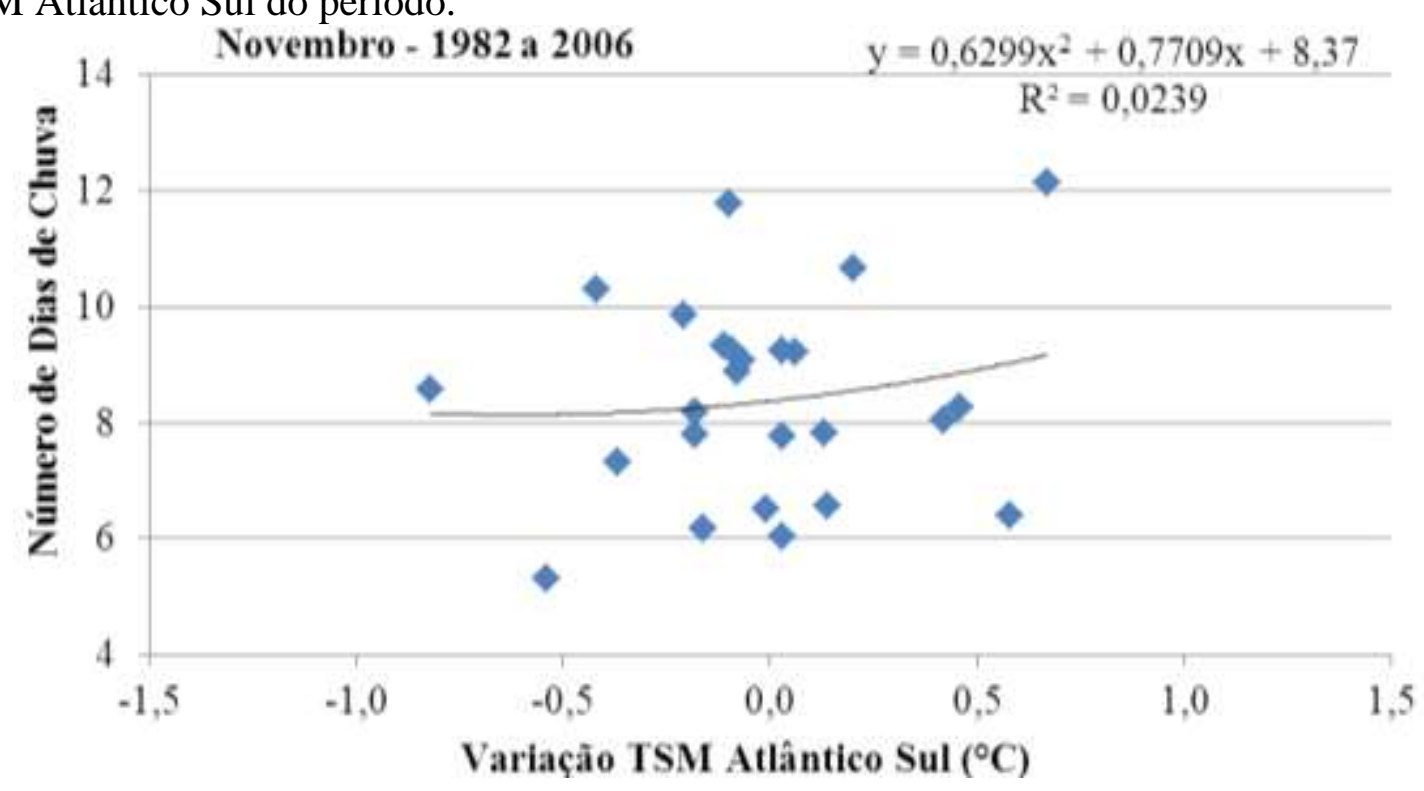

As variações TSM tanto positivas quanto negativas para o mês de dezembro (Figura 15) pouco interferiram no NDC, observou-se apenas durante suas ocorrências um pequeno decréscimo dos dias de chuva. A mais intensa variação TSM negativa $\left(-0,7^{\circ} \mathrm{C}\right)$ provocou 8 dias de chuva no ano de 1992. A mais intensa variação TSM positiva $\left(0,8^{\circ} \mathrm{C}\right)$ ocasionou 10 


\begin{tabular}{|c|c|c|}
\hline & $\begin{array}{r}\text { GEOAMBIENTE } \\
\text { Revista Eletrônica do Curso de Geog } \\
\text { Graduacão e Pós-Graduacă } \\
\text { www2.jatai.ufg.br/ojs/index } \\
\text { Apoio: PRPPG/PROA } \\
\text { | Jataí-GO | n.20 | Ja }\end{array}$ & ISSN $1679-9860$ \\
\hline
\end{tabular}

dias de chuva no ano de 1997. O ano com o menor NDC (5 dias) para este mês foi o de 1985, o qual não estava sob influência de nenhuma variação TSM. O maior NDC (14 dias) foi registrado no ano de $1986\left(-0,1^{\circ}\right)$.

Figura 15 - Dispersão em dezembro do Número de Dias de Chuva em relação à variação TSM Atlântico Sul do período.

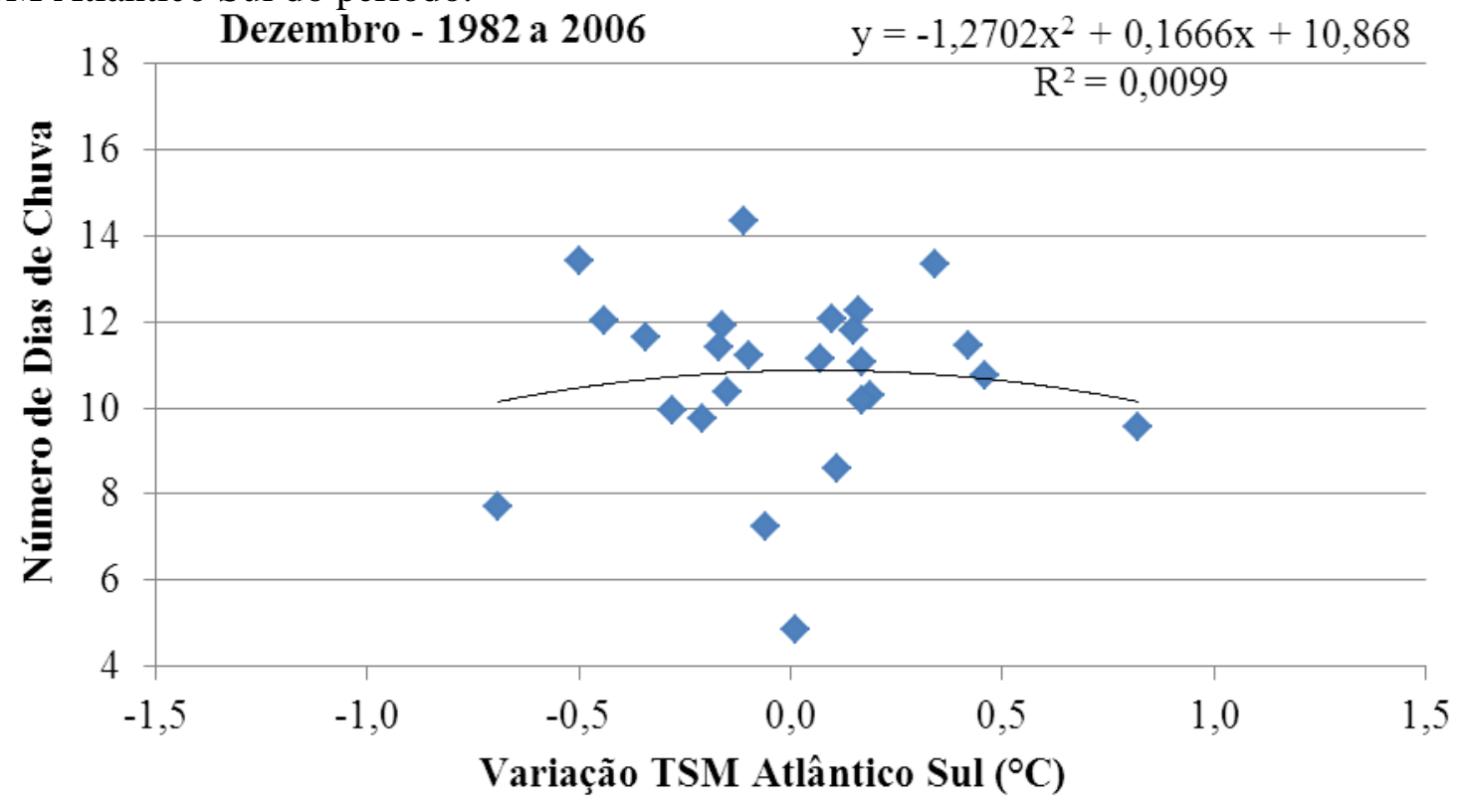

No período de 1982 a 2006 (Figura 16) a Temperatura Superfície do Mar das águas do Oceano Atlântico Sul variaram em média entre $-0,7^{\circ} \mathrm{C}$ e $0,3^{\circ} \mathrm{C}$, como a parábola do gráfico anual está com a concavidade voltada para cima, pode-se afirmar que o NDC cresce conforme aumenta a intensidade da variação TSM. Na Figura 16 o NDC do gráfico se caracteriza com a soma dos dias em que se registrou chuva de cada ano da série histórica. Observa-se que todos os anos do período estiveram sob influência de variações TSM negativas ou positivas, mesmo que sejam mínimas. No geral o NDC de cada ano cresceu e diminuiu proporcionalmente tanto nos episódios de variações TSM negativas quanto nos episódios de variação TSM positiva, não permitindo assim delimitar qual das variações TSM mais influência no NDC. A maior variação TSM negativa média $\left(-0,7^{\circ}\right)$ foi registrada no ano de 1992, no qual dos 365 dias do ano choveram 91 dias. Já a mais forte variação TSM positiva $\left(0,3^{\circ} \mathrm{C}\right)$ foi registrada nos anos de 1984, 1988, 1998 e 2003, nos quais choveu 92, 86, 90 e 86 dias, respectivamente. O ano de 2002 foi o com menor NDC do período (70 dias) e estava sob influência de uma variação 


\begin{tabular}{|c|c|c|}
\hline & $\begin{array}{r}\text { GEOAMBIENTE } \\
\text { Revista Eletrônica do Curso de Geog } \\
\text { Graduacão e Pós-Graduacă } \\
\text { www2.jatai.ufg.br/ojs/index } \\
\text { Apoio: PRPPG/PROA } \\
\text { | Jataí-GO | n.20 | Ja }\end{array}$ & ISSN $1679-9860$ \\
\hline
\end{tabular}

TSM negativa de $-0,2^{\circ} \mathrm{C}$. Dos 365 dias do ano de 1989 choveu em 102 dias, o maior NDC do período e estava sob influência de uma variação TSM positiva de $0,1^{\circ} \mathrm{C}$.

Figura 16 - Dispersão anual do Número de Dias de Chuva em relação à variação TSM Atlântico Sul do período.

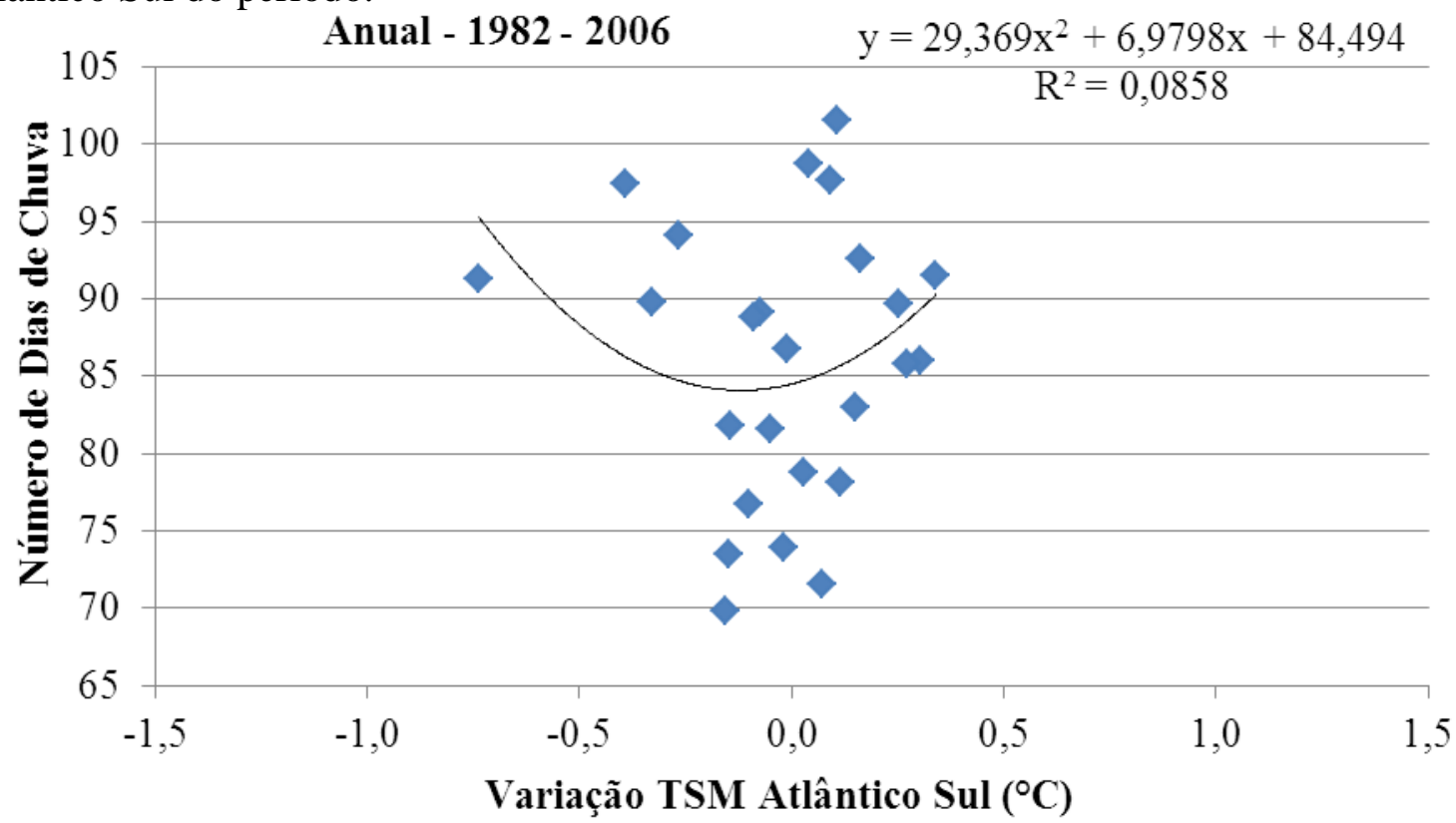

De acordo com a Figura 17 dentro do período estudado (1982-2006) a variação TSM negativa com maior intensidade (variação de $-1,0^{\circ} \mathrm{C}$ na temperatura) aconteceu no ano de 1992 nos meses de maio ( 7 dias de chuva) e junho (3 dias de chuva) e no ano de 1997 nos meses de abril (6 dias de chuva) e maio (4 dias de chuva). A variação TSM positiva com maior intensidade (variação de $0,8^{\circ} \mathrm{C}$ na temperatura) ocorreu no mês de dezembro de 1997 ocasionando 10 dias de chuva. As variações positivas de temperatura são mais freqüentes que as variações negativas, porém as variações TSM negativas acontecem com maiores intensidades que as variações TSM positivas. Além disso, os maiores NDC coincidem com variações TSM positivas.

$\mathrm{Na}$ análise estatística (Tabela 1) verifica-se que o maior NDC do Estado do Mato Grosso do Sul foi obtido no mês de janeiro (aproximadamente 20 dias de chuva) de 1989, quando a variação TSM estava em $0,5^{\circ} \mathrm{C}$ (Figura 4). A tendência central (média), que é o centro de um grupo de números em uma distribuição estatística, para os valores de dias de chuva, mostrou uma maior proximidade com os valores máximos nos meses chuvosos (outubro a abril) em relação aos meses secos, que tiveram maior proximidade com os valores 


\begin{tabular}{|c|c|c|}
\hline & $\begin{array}{r}\text { GEOAMBIENTE } \\
\text { Revista Eletrônica do Curso de Geog } \\
\text { Graduacão e Pós-Graduacă } \\
\text { www2.jatai.ufg.br/ojs/index } \\
\text { Apoio: PRPPG/PROA } \\
\text { | Jataí-GO | n.20 | Ja }\end{array}$ & ISSN $1679-9860$ \\
\hline
\end{tabular}

mínimos. Em todos os meses, verifica-se que a mediana ficou muito próxima da média. A medida do grau de dispersão dos valores em relação ao seu valor médio mostra que, em média, nos meses de maiores dias de chuva o desvio padrão foi maior que nos meses com menores valores. O maior desvio padrão foi obtido no mês de janeiro $(3,0)$, considerado mês úmido, e o menor desvio padrão $(0,9)$ foi obtido no mês de julho, considerado mês seco.

Figura 17 - Influência da variação TSM Atlântico Sul no Número de Dias de Precipitação Pluviométrica do período.

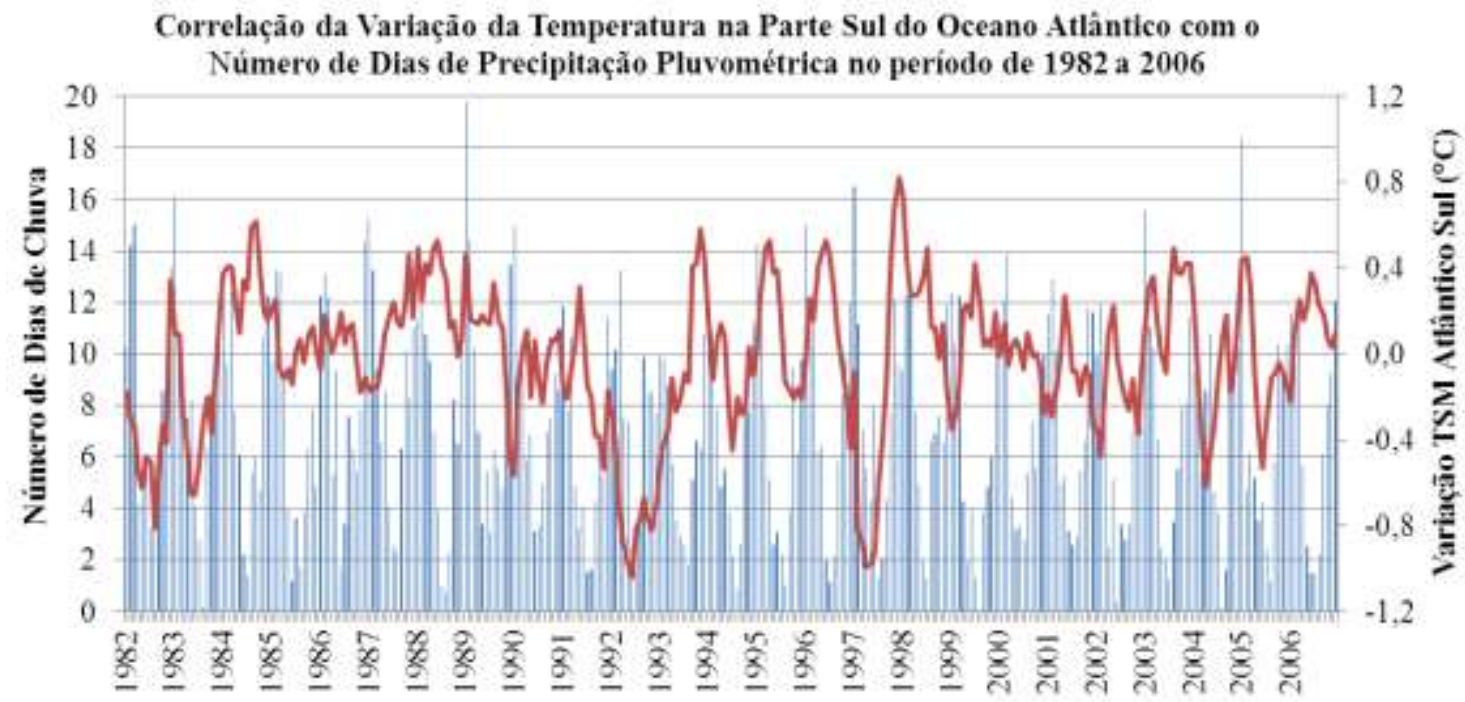

Tabela 1 - Analise estatística do Número de Dias de Chuva do Mato Grosso do Sul.

\begin{tabular}{lrrrrrrrrrrrrr}
\hline Estatística & \multirow{2}{*}{ Jan } & \multirow{2}{*}{ Fev } & \multirow{2}{*}{ Mar } & Abr & Mai & Jun & Jul & Ago & Set & Out & Nov & \multirow{2}{*}{ Dez } & Anual \\
\hline \hline Máximo & 19,8 & 14,5 & 15,0 & 9,7 & 10,7 & 7,9 & 3,8 & 7,6 & 9,9 & 10,4 & 12,1 & 14,3 & 101,5 \\
Média & 12,7 & 11,2 & 10,4 & 6,1 & 5,2 & 3,3 & 2,3 & 2,8 & 5,2 & 7,5 & 8,4 & 10,7 & 86,0 \\
Mediana & 11,9 & 11,1 & 10,3 & 5,7 & 4,9 & 3,1 & 2,5 & 2,2 & 5,5 & 7,7 & 8,3 & 11,2 & 86,7 \\
Mínimo & 9,3 & 4,7 & 5,5 & 2,5 & 1,9 & 0,4 & 1,0 & 0,1 & 1,6 & 4,7 & 5,3 & 4,9 & 69,9 \\
Desvio Padrão & 3,0 & 2,2 & 2,5 & 1,7 & 2,4 & 1,6 & 0,9 & 2,1 & 1,8 & 1,6 & 1,8 & 2,1 & 8,9 \\
\hline
\end{tabular}

\section{CONCLUSÕES}

Os meses de julho, agosto, setembro apresentaram decréscimo ou acréscimo da precipitação conforme a intensidade das variações de TSM do Oceano Atlântico em estudo, mas nada muito significativo. Assim pode-se constatar que nos demais meses do período de 1982 a 2006 as variações TSM pouco interferiram nos dias de chuva para o Estado de Mato Grosso do Sul. Quando alguma influência dos fenômenos foi constatada, observou-se que as variações TSM positivas estão mais associadas à NDC acima da média, enquanto que as variações TSM negativas estão associadas NDC abaixo da média. 


\begin{tabular}{|c|c|c|}
\hline & $\begin{array}{r}\text { GEOAMBIENTE } \\
\text { Revista Eletrônica do Curso de Geog } \\
\text { Graduacão e Pós-Graduacă } \\
\text { www2.jatai.ufg.br/ojs/index } \\
\text { Apoio: PRPPG/PROA } \\
\text { | Jataí-GO | n.20 | Ja }\end{array}$ & ISSN $1679-9860$ \\
\hline
\end{tabular}

Outro fator culminante, para atestar que as variações TSM do Atlântico Sul pouco causam efeitos evidentes nas precipitações do Estado de Mato Grosso do Sul, é o fato de que nos meses de maiores intensidades desses fenômenos as curvas de tendência mantiveram-se praticamente estáveis, ou seja, não houve tendência de acréscimo ou decréscimo do NDC dentro do período em estudo.

\section{AGRADECIMENTOS}

Os autores agradecem à CPRM/SGB (Companhia de Pesquisa de Recursos Minerais / Serviço Geológico do Brasil - empresa pública de pesquisa do Ministério de Minas e Energia) pelo fomento que viabilizou o desenvolvimento deste trabalho.

\section{REFERENCIAS}

EMBRAPA. Empresa Brasileira de Pesquisa Agropecuária. Brasil em Relevo. Disponível em: <http://www.relevobr.cnpm.embrapa.br/download/index.htm>. Acesso em: 02/2012.

FISCHER, G. R.; DINIZ, G. B. eMARQUES, J. R. Q., 2008. Previsão do número de dias de chuva para a metade sul do Rio Grande do Sul utilizando a Temperatura da Superfície do Mar (TSM).Rev. bras. meteorol. [online]. Vol.23, n.2, pp. 146-151. ISSN 0102-7786. http://dx.doi.org/10.1590/S0102-77862008000200003.

FUR.; DICKINSON R.E.; CHEN M.\& WANG H., 2001. Tropical sea surface temperatures influence the seasonal distribution of precipitation in the Equatorial Amazon.J. Clim., 14: 4003-4026.

INSTITUTO BRASILEIRO DE GEOGRAFIA E ESTATÍSTICA - IBGE. Censo 2010. Disponível em: <http://www.ibge.gov.br/cidadesat/link.php?uf=to >. Acesso em: 06/2012.

MENEZES, H. E. A.; BRITO, J. I. B.; SANTOS, C. A. C. e SILVA, L. L., 2008.A relação entre a temperatura da superfície dos oceanos tropicais e a duração dos veranicos no Estado da Paraíba.Rev. bras. meteorol.[online]. Vol.23, n.2, pp. 152-161. ISSN 0102-7786. http://dx.doi.org/10.1590/S0102-77862008000200004.

NAGHETTINI, M.; PINTO, É. J. A.; 2007. Hidrologia Estatística. Belo Horizonte: CPRM. NOAA - National Weather Service (2011)."Monthly Atmospheric \& SST Indices". Disponível em <http://www.cpc.ncep.noaa.gov/data/indices/> Acesso 02/2012.

PEE, L M.C; FINLAYSON, B.L. \& MCMAHON, T.A. Updated world map of the KöppenGeiger climate classification, Hydrol.Earth Syst. Sci., 11, 1633-1644. 2007. 


\begin{tabular}{|c|c|c|}
\hline & $\begin{array}{r}\text { GEOAMBIENTE } \\
\text { Revista Eletrônica do Curso de Geog } \\
\text { Graduacão e Pós-Graduacă } \\
\text { www2.jatai.ufg.br/ojs/index } \\
\text { Apoio: PRPPG/PROA } \\
\text { | Jataí-GO | n.20 | Ja }\end{array}$ & ISSN $1679-9860$ \\
\hline
\end{tabular}

SANTOS, C. A. C., BRITO, J. I. B. Análise dos índices de extremos para o semi-árido do Brasil e suas relações com TSM e IVDN. Revista Brasileira de Meteorologia, v. 22, n. 3, p. 303-312. 2007.

SILVA, A. P. N.; MOURA, G. B. A.; GIONGO, P.R. e MEDEIROS, S. Ricardo R. Correlação entre as Temperaturas da Superfície do Mar e a quantidade da precipitação na estação chuvosa no Nordeste do estado de Pernambuco. Rev. bras. meteorol. [online]. Vol.26, n.1, pp. 149-156. ISSN 0102-7786. http://dx.doi.org/10.1590/S0102$\underline{77862011000100013.2011 .}$

WAGENER, T.; FRANKS, S.; GUPTA, H.V.; BGH, E.; BASTIDAS, L.; NOBRE, C. \& GALVÃO, C.O. Regional hydrological impacts of climate change - impact assessment and decision-making.Wallingford, IAHS. p.1-8. 2005. 